\title{
De novo transcriptome analysis of white teak (Gmelina arborea Roxb) wood reveals critical genes involved in xylem development and secondary metabolism
}

Mary Luz Yaya Lancheros ${ }^{1}$, Krishan Mohan Rai ${ }^{2,3}$, Vimal Kumar Balasubramaniann ${ }^{2,4}$, Lavanya Dampanaboina ${ }^{2}$, Venugopal Mendu ${ }^{2}$ and Wilson Terán ${ }^{*^{*}}$ (D)

\begin{abstract}
Background: Gmelina arborea Roxb is a fast-growing tree species of commercial importance for tropical countries due to multiple industrial uses of its wood. Wood is primarily composed of thick secondary cell walls of xylem cells which imparts the strength to the wood. Identification of the genes involved in the secondary cell wall biosynthesis as well as their cognate regulators is crucial to understand how the production of wood occurs and serves as a starting point for developing breeding strategies to produce varieties with improved wood quality, better paper pulping or new potential uses such as biofuel production.

In order to gain knowledge on the molecular mechanisms and gene regulation related with wood development in white teak, a de novo sequencing and transcriptome assembly approach was used employing secondary cell wall synthesizing cells from young white teak trees.
\end{abstract}

Results: For generation of transcriptome, RNA-seq reads were assembled into 110,992 transcripts and 49,364 genes were functionally annotated using plant databases; $5071 \mathrm{GO}$ terms and 25,460 SSR markers were identified within xylem transcripts and 10,256 unigenes were assigned to KEGG database in 130 pathways. Among transcription factor families, $\mathrm{C} 2 \mathrm{H} 2, \mathrm{C} 3 \mathrm{H}, \mathrm{bLHLH}$ and MYB were the most represented in xylem. Differential gene expression analysis using leaves as a reference was carried out and a total of 20,954 differentially expressed genes were identified including monolignol biosynthetic pathway genes. The differential expression of selected genes ( $4 C L$, COMT, CCOAOMT, CCR and NST1) was validated using QPCR.

Conclusions: We report the very first de novo transcriptome of xylem-related genes in this tropical timber species of commercial importance and constitutes a valuable extension of the publicly available transcriptomic resource aimed at fostering both basic and breeding studies.

Keywords: RNA-seq, Xylem, Differential gene expression, Wood development

\footnotetext{
* Correspondence: wteran@javeriana.edu.co

${ }^{1}$ Department of Biology, Pontificia Universidad Javeriana, Carrera 7 № 43-82, Bogotá 110231, Colombia

Full list of author information is available at the end of the article
}

(c) The Author(s). 2021 Open Access This article is licensed under a Creative Commons Attribution 4.0 International License, which permits use, sharing, adaptation, distribution and reproduction in any medium or format, as long as you give appropriate credit to the original author(s) and the source, provide a link to the Creative Commons licence, and indicate if changes were made. The images or other third party material in this article are included in the article's Creative Commons licence, unless indicated otherwise in a credit line to the material. If material is not included in the article's Creative Commons licence and your intended use is not permitted by statutory regulation or exceeds the permitted use, you will need to obtain permission directly from the copyright holder. To view a copy of this licence, visit http://creativecommons.org/licenses/by/4.0/ The Creative Commons Public Domain Dedication waiver (http://creativecommons.org/publicdomain/zero/1.0/) applies to the data made available in this article, unless otherwise stated in a credit line to the data. 


\section{Background}

Tree wood is considered as a sustainable alternative source for biofuel production [1] in addition to its current use in paper and pulp industries. Manipulation of woody biomass for various applications requires extensive knowledge of the pathways involved in the wood production $[2,3]$. In rice, for instance, edition of a CAD (cinnamyl alcohol dehydrogenase) encoding gene using CRISPR-CAS (Clustered Regularly Interspaced Short Palindromic Repeats- CRISPR Associated Nuclease) technology, altered cell wall compostion, reducing lignin content and increasing both cellulose and hemicellulose, which enhanced significantly the saccharification process [4]. A similar result was achieved in poplar, finding that a reduction in lignin biosynthesis led to an improvement of the biomass quality with higher saccharification efficiency [5]. Gmelina arborea Roxb. (white teak, Malay beechwood, Kashmir tree, gamari or yemane) is a fastgrowing tree species belonging to the lamiaceae family, with tremendous economic importance in several tropical and subtropical areas of southeastern Asia, Africa and America. Its introduction and excellent adaptation to the American tropics (Costa Rica, Venezuela, Colombia and Guatemala) is due to the traits like fast growth, high biomass production $\left(20-25 \mathrm{~m}^{3} / \mathrm{ha} /\right.$ year), less susceptibility to the local pests and high yields in addition to the versatility of its wood use which allow a faster investment return [6]. Therefore, it is considered as a species of choice for both reforestation programs and agroforestry systems in these areas $[6,7]$.

White teak has also shown natural tolerance to water stress and resistance to fire, both characteristics of high interest in the context of climate change. This species has been considered as a tree with higher bioenergetics production, generating an average of $265 \mathrm{~m}^{3}$ of biomass/ ha/year [8]. White teak fruits and seed present interesting potential as sources of oil for biodiesel production whereas its lignocellulosic wastes serves as a source of bioethanol [8-10]. Wood is primarily composed of vascular cambium in the woody plants and is composed mainly by secondary xylem. Xylem allows water transport through the stem as well as the tree branches in addition to providing structural support [11].

Formation of wood xylem cells involves two basic processes occurring simultaneously i.e. formation of the secondary cell-wall and programmed cell death [11]. The secondary cell wall is mainly composed of cellulose, hemicellulose and lignin polymers in various proportions [12]. Cellulose is a linear polymer of beta 1-4 linked glucan units that forms microfibers structures which interacts with complex polymers collectively called hemicelluloses in order to form a reticulated matrix [13]. Lignin is a polyphenolic compound which is hydrophobic in nature filling the spaces between celluloses and hemicellulose fibers and conferring additional mechanical support, rigidity and hydrophobicity [14, 15]. After cellulose, lignin is the second most abundant polymer produced by plants, representing approximately $30 \%$ of the organic carbon in the biosphere [16]. Lignin polymers are produced from the hydroxycinnamyl alcohol (monolignol) pathway derived from phenylpropanoid pathway, which is also a source of other compounds such as flavonoids, coumarins, phytoalexins and lignans that are important for plant defense against biotic stressors and commercial biomolecule production [17, 18]. Lignin plays a significant role in the growth and development of woody species which adds the required strength to grow upright and withstand against the mechanical pressure [15].

Lignin biosynthetic pathway involves eleven enzymes in order to produce three monolignols; $p$-coumaryl alcohol, sinapyl alcohol and coniferyl alcohol [19]. Polymerization of these monolignols produces three types of lignin units, Hydroxyphenyl lignin (H-lignin), Syringyl lignin (S-lignin) and Guaiacyl lignin (G-lignin) and the type of lignin varies based on the species, tissue type and stage of development [12]. The gymnosperm lignin is mainly composed of $\mathrm{H}$ and $\mathrm{G}$ units, while angiosperms lignin from monocots is composed of $\mathrm{H}, \mathrm{G}$ and $S$ units whereas in dicots it is composed of $G$ and $S$ units [20, 21].

Various transcription factors have been identified and characterized as key players of wood development, primarily members of NAC and MYB families involved in the regulation of monolignol pathway and lignin polymerization $[19,22,23]$. The NAC family, the transcription factors SND1, NST1, VND6 and VND7 have been recognized as master switches involved in activation of cascade of transcription factors, converging ultimately into secondary xylem formation and lignification [23, 24], . The MYB family transcription factors appears to directly regulate the lignin biosynthetic as well as other cell wall biosynthetic genes. These MYB transcription factors recognize specific DNA sequence motifs on the promoter or regulatory regions of target genes and thereby activating or repressing transcriptional expression [23-25].

The monolignol pathway has been mainly studied in model plant species such as Arabidopsis and poplar [26, 27]. The knowledge generated from these species, has been used to modify tree species such as poplar and eucalyptus in order to reduce the lignin content [28-30]. Although white teak woody biomass presents a high potential for novel uses, lack of knowledge on metabolic and regulatory genes involved in wood development and lignin biosynthesis impairs its use for biofuel applications. A comprehensive knowledge on lignification pathways and its regulation is essential for the improvement 
of commercially important traits such as wood quality, paper pulping or biofuel production. Therefore, in the present study we have generated de novo xylem transcriptome and analyzed and identified xylem specific metabolic and regulatory genes which serve as target genes for future breeding developments in this species.

\section{Results}

\section{Generation and annotation of a reference xylem transcriptome}

RNA-seq of G. arborea xylem library resulted in approximately 165 million paired reads. Quality filtration for the low-quality reads $(\mathrm{Q}<20)$ and contaminants such as reads of ribosomal and organellar origin resulted in the removal of total of 18,968 paired sequences. The cleaned reads were assembled using Trinity software to obtain the reference transcriptome with 110,992 transcripts. The assembled transcripts showed a considerably higher N50 value of 1466 bases with the average transcript length of 864 bases (Table 1). Various publicly available tools and databases were used to annotate these assembled G. arborea transcripts. A more popular and conventional homology-based annotation with NCBI NR database resulted in 49,364 hits whereas using

Table 1 Summary of assembly and annotation metrics of the reference transcriptome obtained from $G$. arborea secondary xylem

\begin{tabular}{ll}
\hline Assembly & \\
Total number of sequences obtained & $164,737,322$ \\
Number of sequences used for the assembly & $164,718,354$ \\
Number of transcripts obtained post assembly & 110,992 \\
N50 value (in bp) & 1466 \\
Average contig length (in bp) & 864 \\
Putative gene number & 81,269 \\
Number of bases assembled & $\sim 95 \mathrm{M}$ \\
Annotation & \\
Full length ORFs & 17,809 (16\%) \\
Quasi full length ORFs & 14,017 \\
& $(12.6 \%)$ \\
Transcripts with hits in the NCBI NR database & 49,364 \\
(BLASTX) & \\
Transcripts with hits in TAIR10 (BLASTX) & 45,377 \\
Transcripts with hits in Populus trichocarpa database & 46,795 \\
Transcripts with hits in the NCBI NR base (BLASTX) & 45,708 \\
Transcripts with PFAM domains & 64,186 \\
Transcripts classified in gene families & 48,322 \\
Transcripts with GO terms & 39,465 \\
Number of GO terms & 5701 \\
Number of KEGG pathways identified & 130 \\
Number of genes associated to KEGG pathways & 10,256 \\
\hline
\end{tabular}

model plant Arabidopsis thaliana TAIR10 protein database resulted in 45,377 hits representing 15,445 unigenes. A higher percentage of transcripts with functional annotation was obtained with HMMER analysis: 64,186 transcripts presented hits with PFAM database. Figure 1 represents the main Gene ontology (GO) categories assigned for 14,155 unigenes. At the level of cellular component, most of the transcripts were located in the category of organelle whereas at the level of molecular function, the binding and catalytic function categories were the most representative. Cellular and metabolic process were among the most significant biological processes, as well as some categories probably related with dynamic activity in xylem tissue like cell biogenesis, and development processes.

Using the KEGG (Kyoto encyclopedia of genes and genomes) database, 10,256 genes were assigned to 130 metabolic pathways (Table 1 and 2). Biosynthesis of secondary metabolites, ribosomes and transduction of hormonal signals were the pathways with highest number of associated genes. Phenylpropanoid biosynthesis was also in the top 20 of the most representative pathways (Table 2).

\section{Identification of transcription factors, metabolic and regulatory genes involved in the monolignol pathway}

The main families of transcription factors identified in the reference transcriptome are presented in Fig. 2. 101 unigenes were assigned to $\mathrm{C} 2 \mathrm{H} 2,92$ to $\mathrm{C} 3 \mathrm{H}, 79$ to bHLH and 72 to MYB TF families; whereas 240 genes were assigned to the AP2-EREBP (56 genes), Homeobox (54 genes), NAC (45 genes), WRKY (43 genes) and bZIP (42 genes) TF families. Nine biosynthetic genes of the monolignol pathway and transcription factors of different levels of regulation were identified from the reference transcriptome.

Among the NAC transcription factors, putative orthologs of Arabidopsis VND7, SND2 and NST1, reported as "master" regulators, were identified. In the case of MYB transcription factors, MYB46 and MYB83, which were classified as regulators of second level, and MYB20, MYB69 and MYB85 which are directly related with the activation of monolignol biosynthetic genes, were identified. Other important transcription factor encoding genes were found like MYB7, MYB4, MYB32 and $K N A T 7$, all reported as negative regulators, or BES1 a specific activator of the synthesis of celluloses (Table 3). In order to clarify the relation and identity of NAC transcription factors identified as VND7, SND2 and NST1, a phylogenetic analysis using possible orthologs from other species was performed (Fig. 3).

In dendrogram (Fig. 3), the transcription factor SND2 of white teak was related to orthologs from other plant species, while NST1 presented a closer phylogenetic 


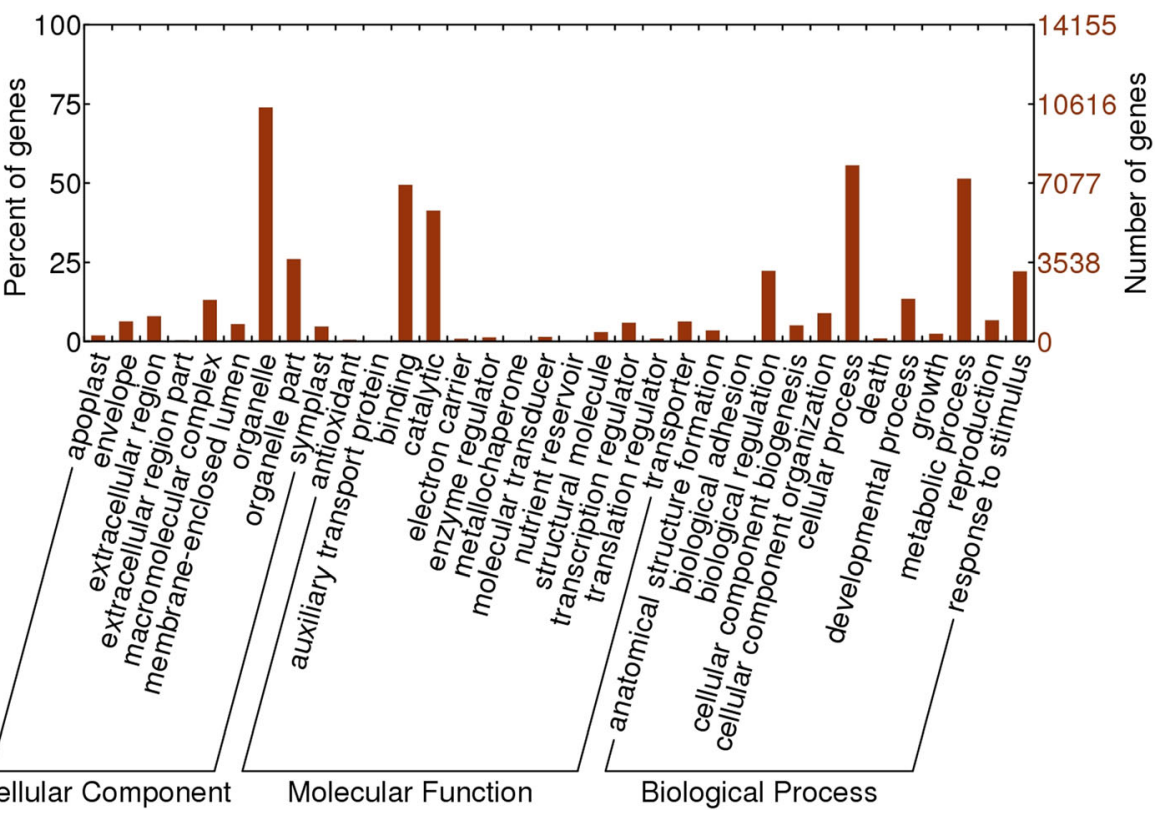

Fig. 1 Main GO categories assigned to xylem reference transcriptome of G. arborea

Table 2 Top 20 KEGG pathways identified in the G. arborea xylem transcriptome

\begin{tabular}{ll}
\hline Pathways identified & Number of genes \\
\hline Metabolic pathways & 1841 \\
Biosynthesis of secondary metabolites & 1020 \\
Ribosome & 346 \\
Transduction of signals of plant hormones & 262 \\
Carbon metabolism & 256 \\
Aminoacid biosynthesis & 251 \\
Protein processing in endoplasmic reticulum & 217 \\
starch and sucrose metabolism & 194 \\
Spliceosome & 189 \\
RNA transport & 165 \\
Purine metabolism & 156 \\
Plant-pathogen interaction & 154 \\
Phenylpropanoid biosynthesis & 152 \\
Oxidative phosphorylation & 149 \\
Ubiquitin mediated proteolysis & 148 \\
Endocytosis & 140 \\
Amino sugar and nucleotide sugar metabolism & 135 \\
Glycolysis / Gluconeogenesis & 113 \\
Pyrimidine metabolism & 112 \\
Cysteine and methionine metabolism & 112 \\
\hline
\end{tabular}

relationship with the NST1 transcription factor of Arabidopsis. In the case of white teak VND7 transcription factor, it was least related with the corresponding orthologs from other species.

Identification of single sequence repeats (SSRs) markers A total of 25,460 exonic SSR markers were identified with 2-5 nucleotides repeat motifs. Among them, the most predominant repetitions were dinucleotides (DNRs, 20,634) and trinucleotides (TNRs, 4463) (Supplementary Table 2). In the case of DNRs, AT and AG were the most abundant motifs (33\%) followed by GA and TA (29\%). Among TNRs, GAA (4.9\%), AAG (4.7\%), TTC (4.0\%) and CCG (3.7\%) were the most abundant motifs.

\section{Differential expression analysis}

With the goal to perform the differential expression analysis between xylem and leaves, we first generated a unique combined transcriptome using the reads from both tissues, since no reference genome sequence is available for G. arborea. A total of 196,317,195 sequences were obtained from leaves; after removal of contaminants and low-quality sequences (about 50 millions of reads), 147,130,884 sequences were obtained. For generation of combined transcriptome, the sequences obtained from leaves were fused with the sequences obtained from xylem. The mapping of reads against this transcriptome indicated an average alignment percentage of $95 \%$, which is indicative of a good representability of expressed transcripts in the 


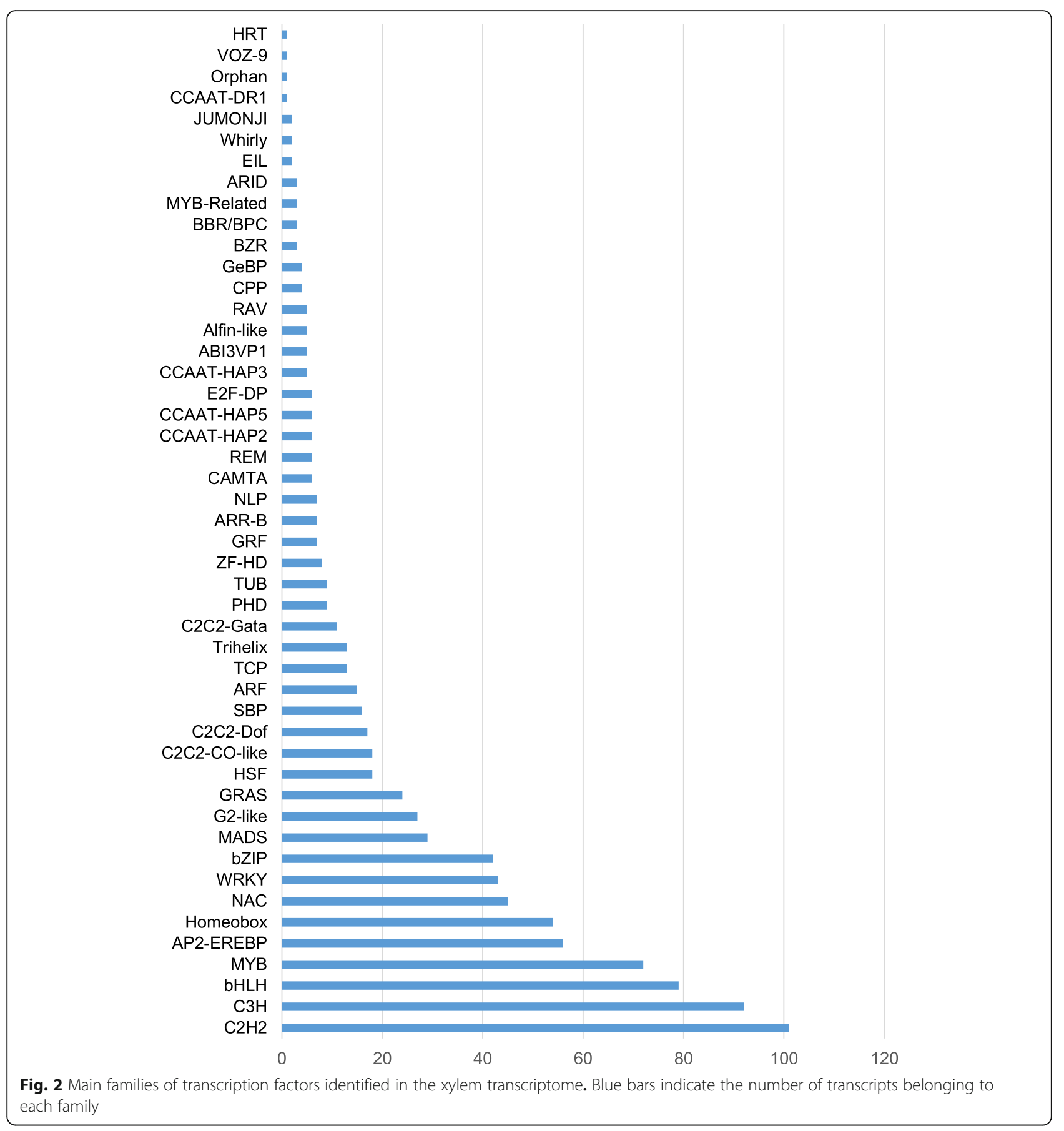

transcriptome. Metrics related with the assembly and annotation of this transcriptome are shown in supplementary Table 1.

Using this unique transcriptome as reference, the differential expression analysis between leaves and secondary xylem (stem) was performed using leaf tissue as a control. Principal component analysis (PCA) of transcript expression levels revealed a clear differentiation of the samples according to the tissue type (supplementary Fig. 1). Results, also indicated that 38,350 transcripts were differentially expressed (adjusted $p$ value $<0.05$ ), out of which 20,964 showed $\log 2$ fold change $\left(\log _{2} \mathrm{FC}\right)$ absolute values higher than 2 as a threshold: 9011 transcripts showed an induction pattern whereas 11,953 were repressed in xylem compared to leaf tissue (Fig. 4). Main functional categories of DEGs are shown in supplementary Fig. 2.

To identify overall changes in xylem metabolic pathways encoded by these DEGs, the Mapman tool was used, using the same $\log _{2} \mathrm{FC}$ thresholds values 
Table 3 Genes related with lignin biosynthesis and its regulation, identified in the xylem reference transcriptome

\begin{tabular}{|c|c|}
\hline Group & Identified genes \\
\hline \multirow[t]{9}{*}{ Monolignol pathway genes } & Phenylalanine ammonia-lyase (PAL) [EC:4.3.1.24] \\
\hline & Cinnamyl alcohol dehydrogenase (CAD) [EC:1.1.1.195] \\
\hline & Ferulate 5-hydroxylase (F5H) [EC:1.14.-.] \\
\hline & Hydroxycinnamoyl-CoA reductase (CCR) [EC:1.2.1.44] \\
\hline & Caffeic acid O-methyltransferase (COMT) [EC:2.1.1.68] \\
\hline & 4-coumarate-CoA ligase (4CL) [EC:6.2.1.12] \\
\hline & p-hydro-xycinnamoyl-CoA (HCT) [EC:2.3.1.133] \\
\hline & caffeoyl-CoA O-methyltransferase (CCOAOMT) [EC:2.1.1.104] \\
\hline & p-coumarate 3-hydroxylase $\left(\mathrm{C}^{\prime} H\right)$ [EC:1.14.13.36] \\
\hline \multirow[t]{12}{*}{ MYB transcription factors } & MYB46 \\
\hline & MYB61 \\
\hline & MYB83 \\
\hline & MYB103 \\
\hline & MYB4 \\
\hline & MYB7 \\
\hline & MYB32 \\
\hline & MYB52 \\
\hline & MYB20 \\
\hline & MYB63 \\
\hline & MYB69 \\
\hline & MYB85 \\
\hline \multirow[t]{3}{*}{ NAC transcription factors } & SND2 \\
\hline & VND7 \\
\hline & NST1 \\
\hline BES1/BZR1 transcription factors & BES1 \\
\hline KNOX transcription factors & KNAT7 \\
\hline
\end{tabular}

$\left(\left|\log _{2} \mathrm{FC}\right| \geq 2\right)$. Figure 5 presents a general outlook of induction and repression patterns of transcripts involved in main primary and secondary cell metabolism.

As expected, genes involved in photosynthetic light reactions were clearly repressed in xylem compared to leaves, whereas those related to respiration were induced. Accordingly, genes related to cell wall synthesis tend to show an induction pattern in stem compared to leaves. Analysis of nine genes of the monolignol pathway showed a clear differential expression between leaves and xylem (Fig. 6). A general pattern of higher expression was identified for the PAL,C4H, COMT and $C C O A O M T$ genes in xylem, while the HCT gene was repressed compared to leaves. In the case of $4 C L, F 5 H$, $C C R$ and $C A D$ different transcripts (associated in various cases with possible splicing isoforms) of the same gene presented a higher expression in one or other tissue.

Additionally, transcripts encoding transcription factors belonging to MYB, NAC and homeobox families, were differentially expressed (Fig. 7). A clear induction of transcripts annotated as members of MYB family was observed in xylem. In the case of NAC family, several transcripts encoding NST1 transcription factor, were induced in xylem whereas one VND7 homolog showed a repression pattern in xylem. Finally, KNAT7, a member of the homeobox family, was also induced in xylem tissue. Other genes involved in the development of secondary cell wall also showed differences between leaves and xylem (Fig. 8). These genes were further classified into five groups based on their function: cellulose synthesis, hemicellulose synthesis, laccases, programed cell death and others.

\section{Identification of paralogs and their respective splice variants of genes of monolignol pathway}

Genes of monolignol pathway contain several variants or paralogs, which may be involved in the same function or have different functions. The reference transcriptome and the differential expression analysis allowed the identification of these paralogs and their possible splicing 


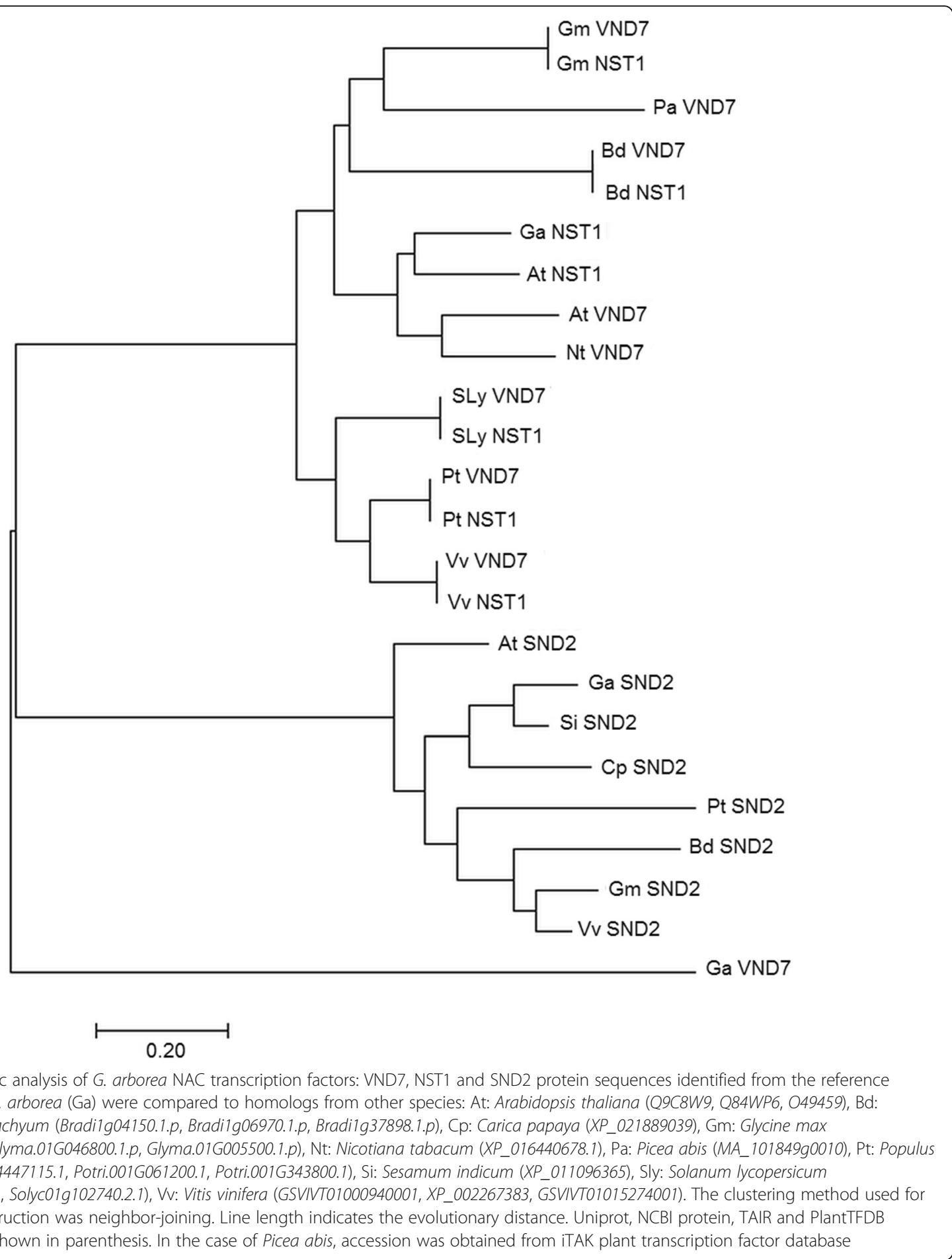

isoforms for some of the monolignol pathway genes. In the case of PAL, two possible paralogs PAL1 and PAL4 were identified and both generated different splicing isoforms, all of them upregulated in stem. In the case of $C A D$, possible orthologs of $C A D 9$ and $C A D 3$ were identified; the putative $C A D 9$ paralog was expressed in both tissues, whereas the CAD3 was expressed only in stem.
Additionally, other two genes, previously not reported, showed a contrasting pattern of expression between tissue: for $4 C L$, two transcripts $4 C L 1$ and $4 C L 2$ were identified as possible variants; the last one was induced in leaf, while $4 C L 1$ was mainly induced in stem. Similarly, CCOAOMT presented two possible variants CCOAOMT1 and CCoAOMT2. No gene or transcript variants were 


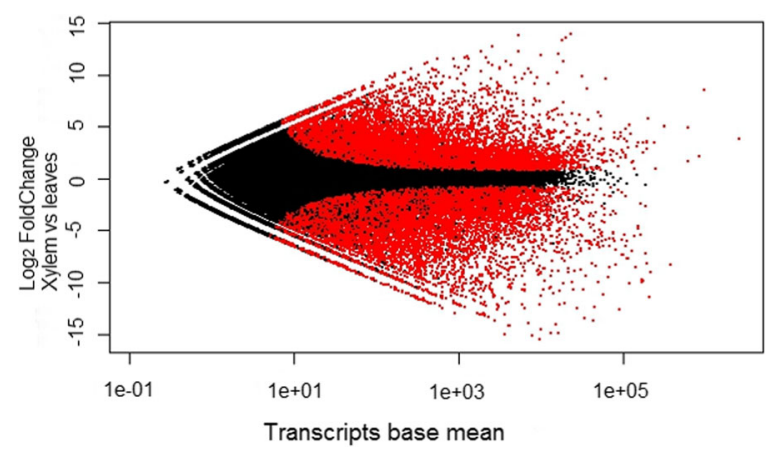

Fig. 4 Distribution of differentially expressed transcripts (DEG) with a $p$-value $<0.05$. DEG are shown in red and the non-DEG are shown in black detected for $C 4 H$, COMT, $F 5 H, C C R$, and $H C T$, as a single transcript was identified.

\section{Phylogenetic analysis}

In order to determine the phylogenetic relations of some genes of the monolignol pathway identified in white teak with homologous sequences reported for different species, a dendrogram was generated using the protein sequences obtained from G. arborea $P A L$ and $C A D$ genes with full length ORFs. These genes are the first (PAL) and the last $(C A D)$ ones to be involved in the monolignol pathway and are key players for the lignin biosynthesis. In the case of $P A L$, one variant induced in stem (putative PAL1) was selected, while for $C A D$, two variants were included: one upregulated in stem (called $C A D S$ and identified as putative $C A D 3$ ) and another one upregulated in leaf (called $C A D L$ ) (Fig. 9A and B).

In the case of PAL, white teak protein formed a single cluster with another possible ortholog of a Lamiaceae

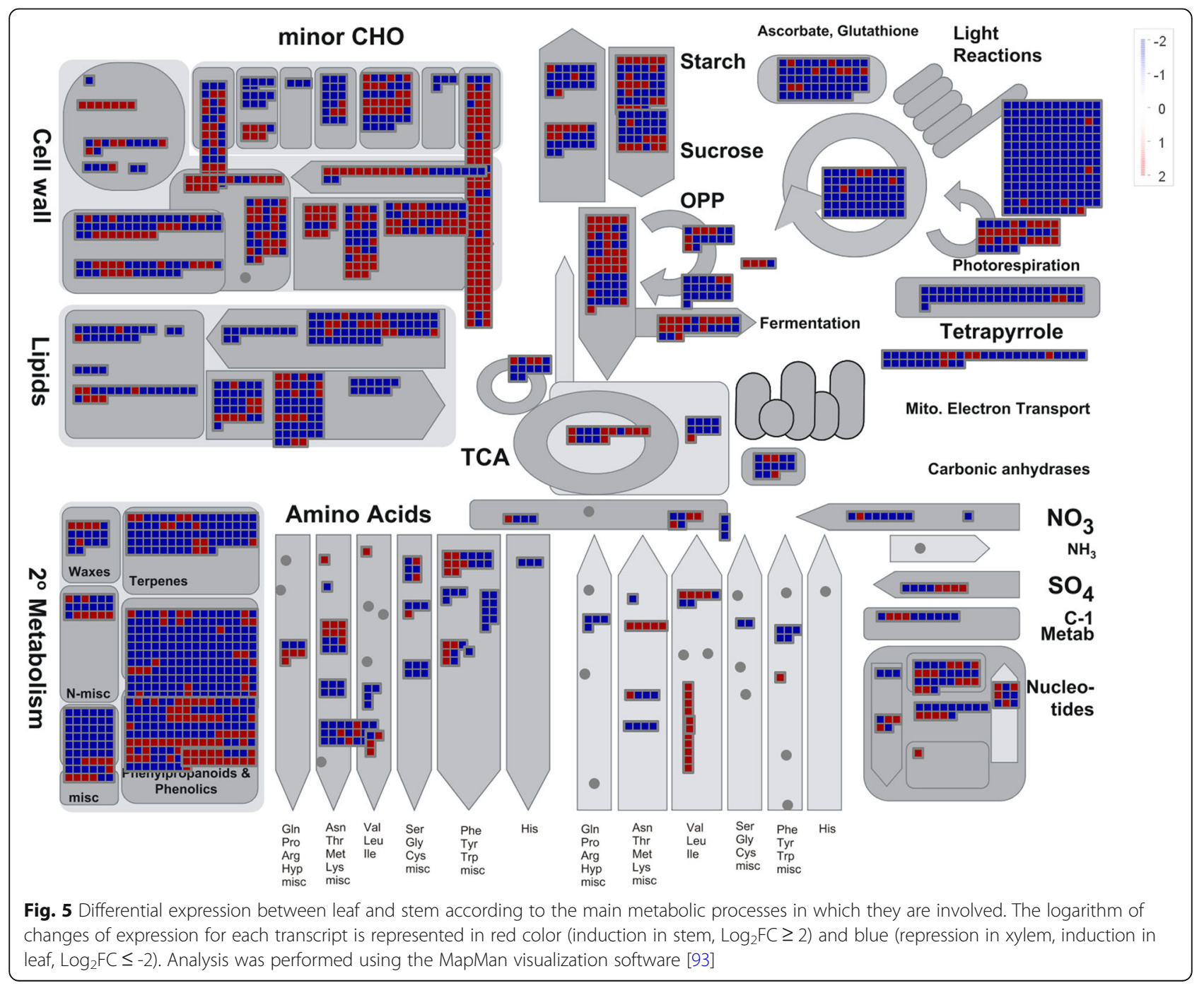




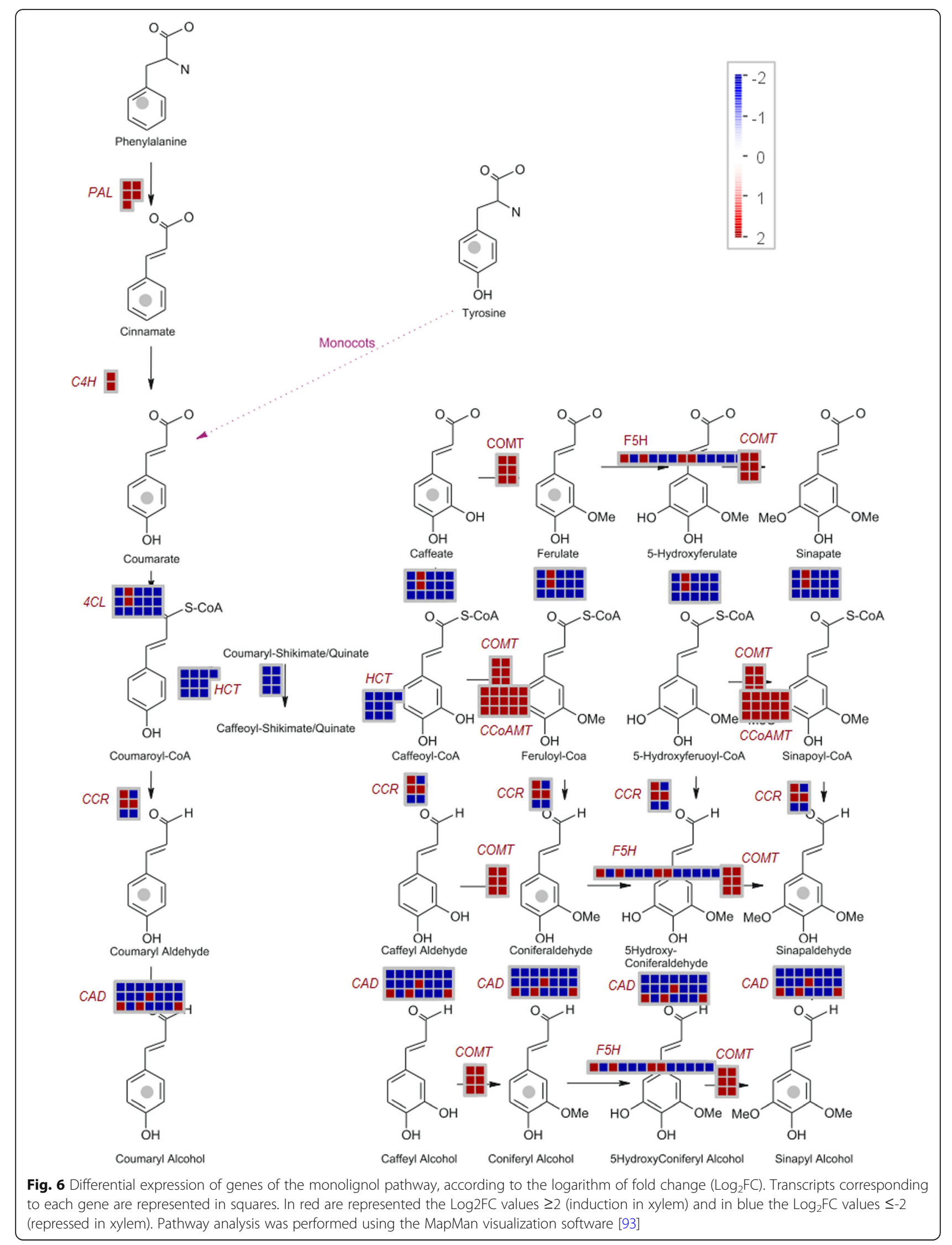




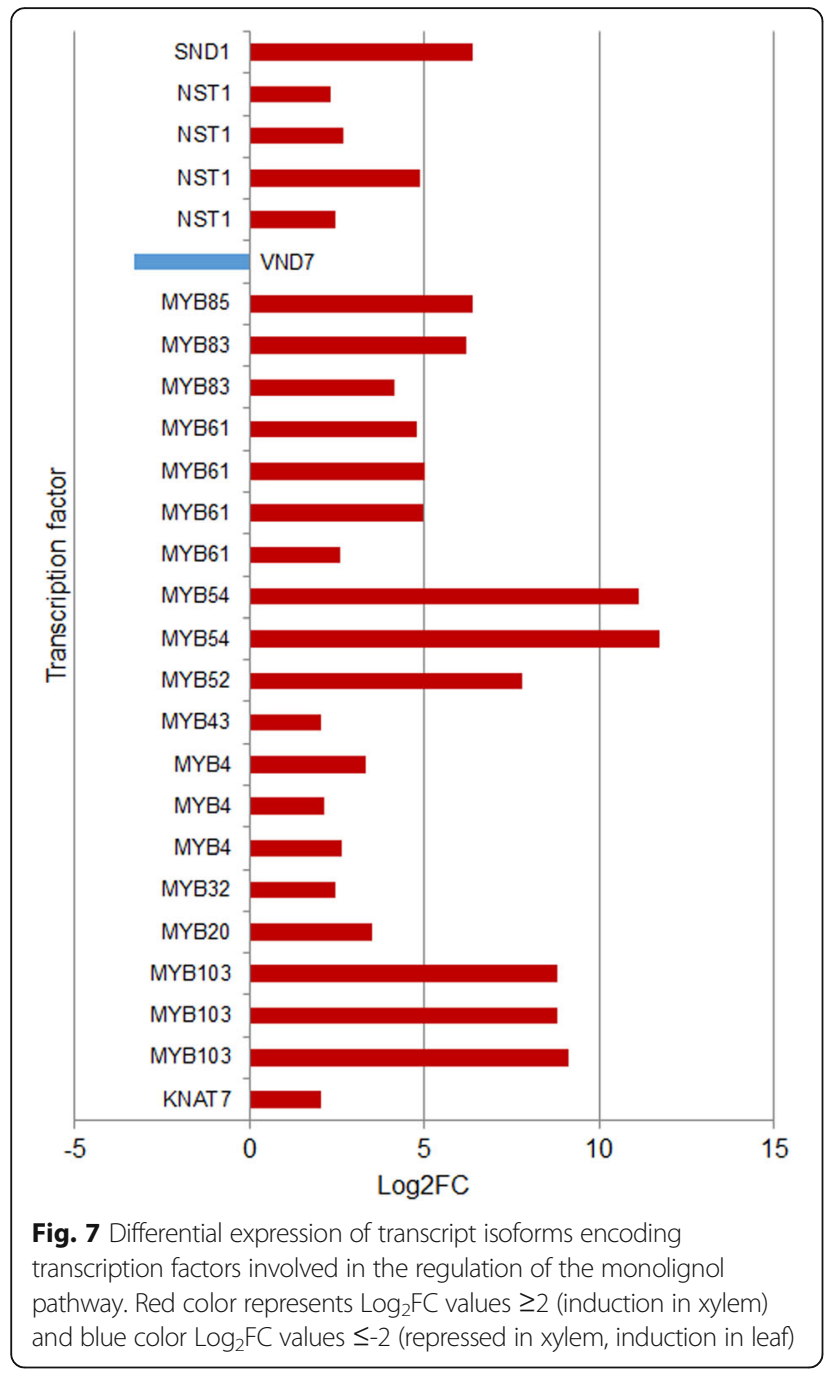

family member, Scutellaria baicalensi, and also with PAL1 of Coffea arabica (Rubiaceae). For CAD protein, the two evaluated white teak members appeared in different but closely located clusters where CADS was most related with CAD of Salvia miltiorrhiza and Sinopodophyllum hexandrum, while CADL was most related with CAD of Sesamum indicum and CAD4 of Tectona grandis (teak), two species belonging to lamiales order . CAD1 and CAD4 from T. grandis (Lamiaceae), a species closely related to $G$. arborea, were located in distant clusters, indicating a high degree of divergence amongst homologous members of this protein family.

\section{Differential expression validation using quantitative reverse transcription PCR (RT- qPCR)}

In order to validate the patterns of differential expression observed, a total of 12 genes (10 upregulated and 2 downregulated) were selected for GPCR validation: seven from metabolic genes of the monolignol pathway, two from regulatory genes (transcription factors) and three

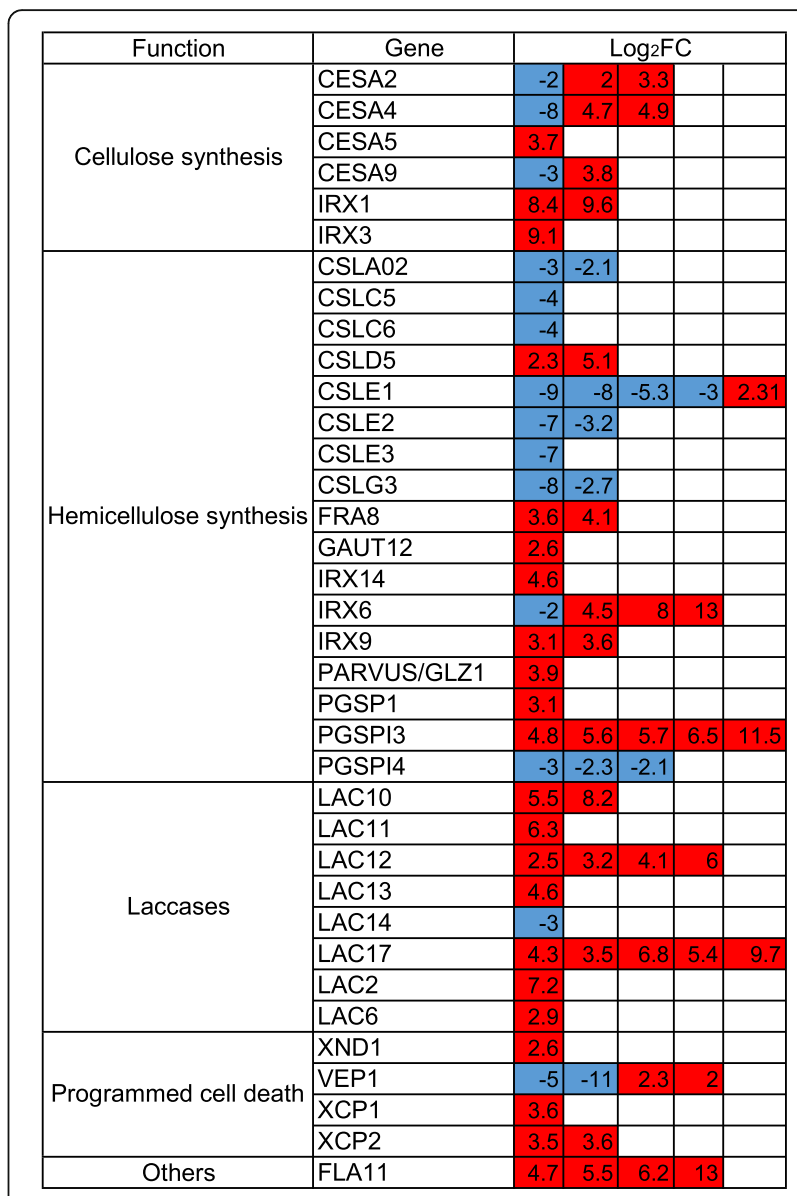

Fig. 8 Genes related to the synthesis of other elements of the secondary cell wall with differential gene expression between stem and leaf. Red color represents $\log _{2} \mathrm{FC}$ values $\geq 2$ (induction in xylem), blue colors $\log _{2} F C$ values $\leq-2$ (repressed in xylem). $\log _{2} F C$ values of all transcript isoforms of the same gene are presented

genes related with synthesis of celluloses and hemicelluloses. For each case, the genes were selected based on the $\log _{2} \mathrm{FC}$ values obtained previously. Comparing the values between the fold change observed in RT-qPCR and the fold change of gene expression obtained by RNA-seq, a concordance was found between the values for the COMT, CCR and NST1 genes. A similar trend in the expression pattern was found for CCoAOMT, $4 C L$, $H C T$ and $C A D$ genes (induced in leaf) (Fig. 10) however, no concordance between $\log _{2} \mathrm{FC}$ values was found for the MYB85, PAL, CESA, FRA8 and PGSIP3 genes (data not included). Correlation analysis between the values of $\log _{2} \mathrm{FC}$ of genes with concordant patterns indicated a moderate general correlation coefficient of 0.50 .

\section{Discussion}

In Colombia, white teak plantations are located mainly in the dry tropical Caribbean zone area, characterized by the presence of a bimodal rainfall pattern, in which the 


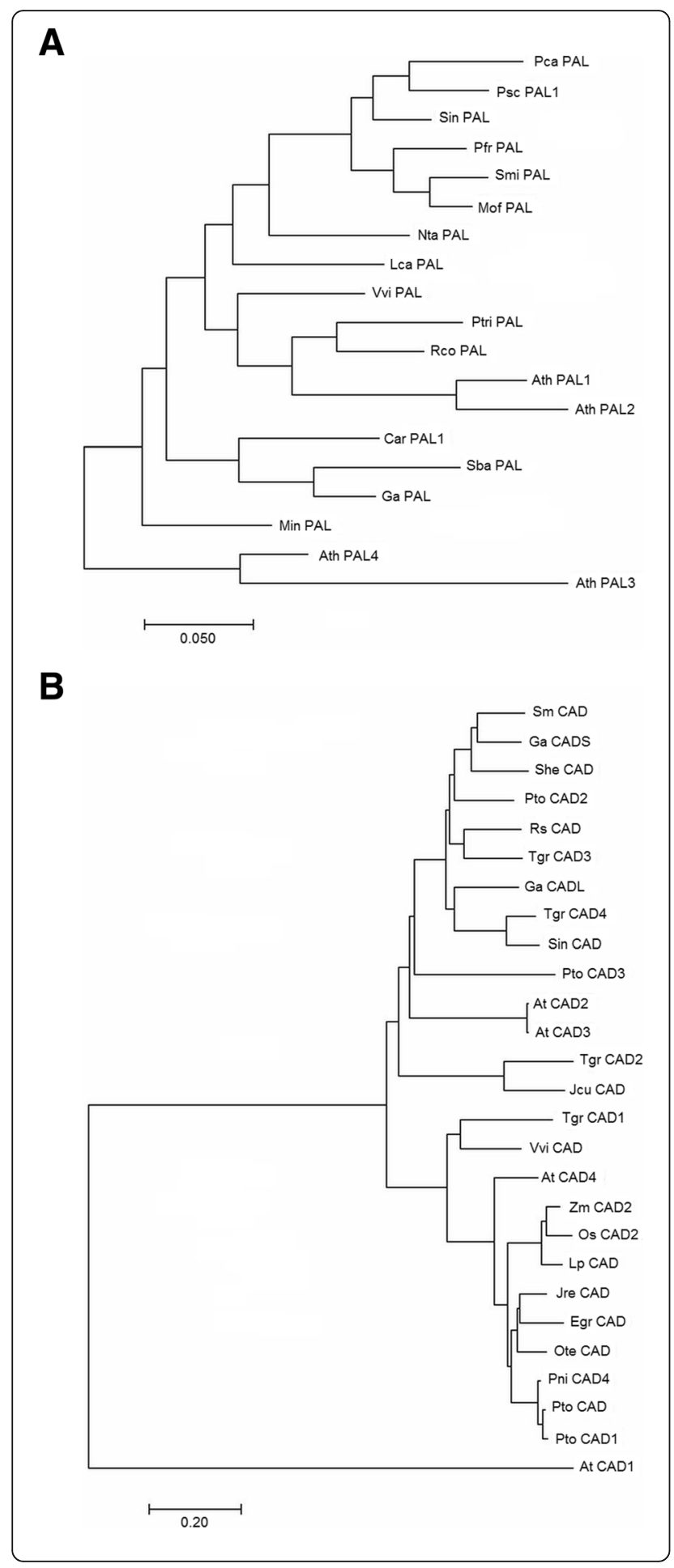

Fig. 9 Phylogenetic analysis of G. arborea PAL (A) and CAD (B) proteins. Protein sequences of PAL and CAD enzymes obtained from G. arborea full length cognate transcripts were compared to homologous sequences belonging to other plant species. Dendrograms were constructed using the neighbor-joining clustering method. Line length indicates the evolutionary distance. In addition to $\mathrm{G}$. arborea (Ga) putative PAL1 sequence, other protein sequences used in PAL phylogenetic analysis were: Ath: Arabidopsis thaliana, with four paralogs of PAL included in the analysis, AthPAL1 (P35510), AthPAL2 (OAP06573), AthPAL3 (OAO94639) and AthPAL4 (OAP02490.1). Car: Coffea arabica (AEL21616), Lca: Lonicera caerulea (ALU09327), Nta: Nicotiana tabacum (NP_001312352.1), Min: Mangifera indica (AlY24975.1), Mof: Melissa officinalis (CBJ23826.1), Pfr: Perilla frutescens (AEZ67457.1), PSC: Plectranthus scutellarioides (AFZ94859.1), Pca: Pogostemon cablin (AJ053272.1), Ptri: Populus trichocarpa (P45730), Rco: Ricinus communis (AGY49231.1), Smi: Salvia miltiorrhiza (ABD73282), Sba: Scutellaria baicalensis (ADN32766.1), Sin: Sesamum indicum (XP_011094662), Vvi: Vitis vinifera (ABM67591), Protein sequences used in CAD phylogenetic analysis, included two possible variants of Gmelina arborea (Ga), the first one induced in stem (CADS, putative $C A D 3$ ) and the second one induced in leaves (CADL). Other CAD protein sequences used were: Ath: Arabidopsis thaliana CAD1 (OAP16446.1) and CAD2 (NP_179765), Egr: Eucalyptus grandis (XP_010024064.1), Jcu: Jatropha curcas (XP_012086572.1), Jre: Juglans regia (XP_018827699.1), Lp: Lolium perenne (AAB70908), Ote: Ocimum tenuiflorum (AD016245.1), Os: Oryza sativa (Q6ZHS4), Pni: Populus nigra (AFR37935.1), Pto: Populus tomentosa (AAR83343.1), Rs: Rauvolfia serpentine (ALW82980.1), Sm: Salvia miltiorrhiza (ADN78309.1), Sin: Sesamum indicum (XP_011097452.1), She: Sinopodophyllum hexandrum (AEA36767.1), Tgr: Tectona grandis (ANG60951.1, ANG60952.1, ANG60953.1, ANG60954.1), Vvi: Vitis vinifera (RVW57228.1), Zm: Zea mays (NP_001105654). Different CAD members were included for some species. Accession IDs from protein NCBI database are shown in parenthesis

plants are frequently subjected to drought periods that can affect the establishment of new plantations and yields [31]. During water stress conditions, it is common to find that the wood lignification patterns are also modified; these modifications have been related with morphological changes in structures like vessels, necessary for an adequate hydraulic conductivity [32]. However, the molecular mechanisms involved in this type of responses are not very clear yet; therefore, it is important to bring knowledge about this type of mechanisms, especially in timber species of high importance, like white teak, whose plantations are frequently under stress conditions. There are only a few species such as Eucalyptus sp [33], Populus sp [34] and Pinus radiata [35] with reported transcriptomic data from xylem, probably due to the difficulty in tissue collection. Further, for tropical timber non-model species, genomic information is still scarce except for some species like acacia [36] and teak [37-39]. Hence, this pioneering study provides information at genomic level associated with development of wood in a non-model tropical species like G. arborea Roxb.

The xylem transcriptome contains 110,992 transcripts, up to $60 \%$ of these could be annotated using different 


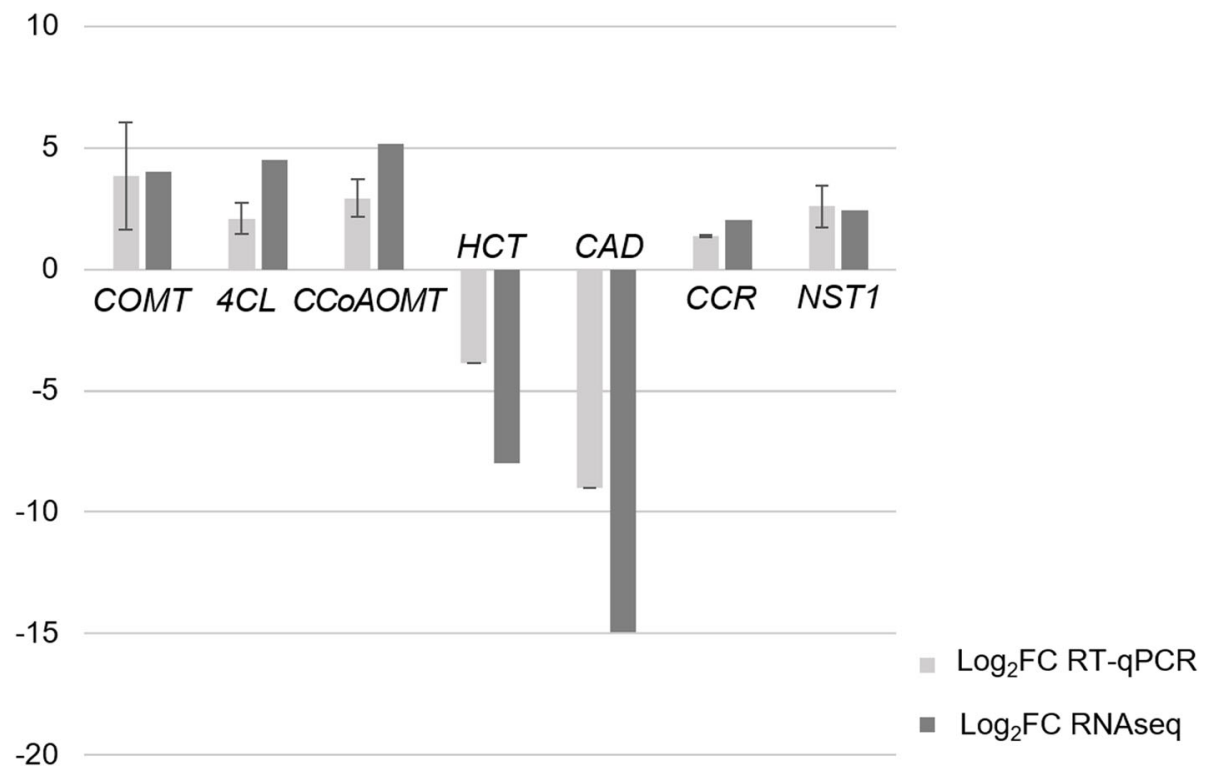

Fig. 10 RT-qPCR differential expression validation of a selection of seven G. arborea genes. Bars indicate log2FC of xylem expression compared with leaf expression: black bars, mean $\log _{2}$ FC values obtained from RT-qPCR assays; gray bars, mean $\log _{2}$ FC values obtained from RNA-seq data

annotation methods (GO, protein domains, BLASTX, KEGG), and also generated a high percentage of transcripts with full length ORFs (16\%) and quasi full length ORFs (12,6\%). GO annotation revealed binding and catalysis as main enriched molecular functions. In the binding category, genes related to transcription factors predominated, indicating that this function is critical for the development of white teak's xylem, while in the catalysis GO category, the importance of different metabolic processes ocurring in this tissue is reflected. One of the most represented category in KEGG pathway was the phenylpropanoid pathway which gives rise to secondary metabolites that are important for different biological processes like pigmentation, UV protection, or responses to pathogens [17]. Additionally, this pathway also produces the monolignols, which are the components of the lignin polymers. Therefore, the results obtained indicate, as expected, a high activity for the pathways involved in the formation of lignin in the developing wood. The de novo transcriptome assembly approach allowed to identify and annotate nine of the ten metabolic genes of the monolignol pathway, which are involved not only in lignin formation but also in other biological processes [40]. Further functional characterization of these individual genes and their variants will provide more information on their biological importance.

\section{Analysis and identification of exonic SSR markers}

Identification of genetic polymorphisms from transcriptomic data, like SSRs markers, is also relevant for a nonmodel species as it can be used in future studies for associating genotype/phenotype oriented towards germplasm bank characterization and breeding processes. The analysis of SSRs markers in the white teak xylemtranscriptome indicated a predominance of the dinucleotides AT and AG, which is in accordance with studies in different dicot and gymnosperms species [41]. The xylem transcriptome of white teak showed the GAA/ AGG (9.9\%) repetitions and TTC/CCG (7.7\%) as the most common SSRs. The AGG motif has been reported as highly frequent in monocot species [42], while GAA has been identified mainly in regulatory regions in Arabidopsis [43]. It has been reported that trinucleotides are less common than dinucleotides; however, their presence in coding regions, may be related to functional polymorphisms while maintaining intact open reading frames.

\section{Analysis of wood and secondary cell wall developmental genes}

In order to identify genes more specifically related with the wood development in white teak, the transcriptional profiles of growing trunks (secondary xylem) and leaves from young trees were contrasted. Differential expression analysis evidenced that, in the case of leaves, various transcription factors, predominantly upregulated, were related to leaf development and photomorphogenesis processes such as $K A N$ family members that have been related to the abaxial identity [44], MYB-like related to foliar senescence [45] and ELF3 related to development and flowering [46]. In the case of xylem, the significant activation of genes related to development of secondary cell wall was evidenced, which is in accordance with the developmental stage or maturity of the sampled trees. 
Analysis of the transcription factors involved in the regulation of secondary cell wall biosynthesis showed that $\mathrm{C} 2 \mathrm{H} 2$ and $\mathrm{C} 3 \mathrm{H}$, which are involved in the hormonal signal transduction process and different processes of development and response to stress in plants were the most abundant [47, 48]. Further, the $M Y B$ and NAC families, which are involved in different biological processes like response to biotic and abiotic stress, cell cycle control, amongst others $[49,50]$ were highly represented. These transcription factor families act like "master" regulators at different levels in the secondary cell wall development. Particularly, members of the NAC family of transcription factors such as SND2, VND7 and NST1 act as activators in the third and second level of the regulatory network [51]. The MYB transcription factors act as activators and repressors of secondary cell wall biosynthetic genes [52, 53]. Interestingly, members of all the above families were represented and upregulated in the stem xylem of white teak.

The secondary cell wall master regulator NAC transcription factors showed a general significant pattern of induction in stems was observed for NST1 and SND2 genes, whereas the transcript annotated as VND7 was downregulated. NST1 is involved mainly in the regulation of development of xylem fibers as has been reported for different species like Arabidopsis and Poplar [15, 54]. In the case of VND7, although, it has been mainly related to regulation processes in the secondary cell wall formation of vessels [53], its low expression in stem could indicate that its role may be dynamic. This is in agreement with the observation by Mitsuda et al. [54], who affirm that although NST and VND are similar in their functions, there are some differences in the way in which they act during the formation of the secondary cell wall, being the NST factors more consistant in their expression and VNDs more variable. However, it is necessary to validate the identity of this transcription factor, because the phylogenetic analysis was inconclusive. The direct downstream targets of NST1, MYB family of transcription factors such as MYB46, MYB61, MYB83 and MYB103 were significantly induced in stem. These transcription factors are involved in regulating other factors such as MYB52 and SND2, related with the direct upregulation of secondary cell wall biosynthetic genes [52], as well as MYB family belonging repressors, like MYB4, MYB7 and MYB32. Genes encoding other downstream acting MYB factors, directly related with the regulation of the lignin synthesis, were upregulated in stem, such as MYB20, MYB63, MYB69 and $M Y B 85$. Interestingly, the repressor genes KNAT7 and MYB4 were also found to be significantly induced in stem, which suggests the presence of negative feedback control loops induced along the development processes of $G$. arborea secondary cell wall.

\section{Analysis of lignin biosynthetic genes}

Specifically, the phenylpropanoids pathway showed a clear pattern of upregulation in xylem compared to leaves, as exemplified by $P A L, C 4 H, C O M T$ and CCoAOMT genes (Fig. 6). However, some variants of biosynthetic genes behave differently. Homologous genes or transcript variants contribute to functional redundancy as well as phenotypic plasticity, where specialization may take place, giving rise to organ or environmental dependent expression. In the case of the $P A L$ gene, four variants have been reported in Arabidopsis (PAL1, PAL2, PAL3 and PAL4) [55], all of them with high importance in the process of lignin biosynthesis. Whereas in tobacco, it has been reported that PAL2 is more related to processes of development of leaves and flowers as well as pollen viability [40]. In our transcriptomic profiling, unique white teak's variants for COMT and $\mathrm{C} 4 \mathrm{H}$ were identified and both were significantly upregulated in stem, whereas $F 5 H$ and $4 C L$ were expressed in both tissues, which does not exclude the possible presence of other variants or multi-functionality of a same variant in other tissues or developmental process.

In the case of CAD enzyme, which catalyzes the last step of the biosynthesis of monolignols for the formation of the alcoholic forms, 9 different members have been reported in Arabidopsis and 12 in rice, some of them with different patterns of expression among different types of tissues $[40,56]$. In the xylem of white teak 4 possible variants of $C A D$ gene were identified, among which $C A D 3$ showed a predominant expression in stem and $C A D 9$ was equally expressed in both tissues, which could indicate a multifunctional role for this gene. $C A D 9$ has been related mainly to the lignification processes [57], with a gradual induction pattern during stem developmental stage succession [58], although its expression has also been evidenced in leaves and as part of stress response mechanisms [58-60]. The identity of the other two possible $C A D$ members was not determined, however both of them were predominantly expressed in leaves of white teak. Besides, some Arabidopsis variants of $C A D$ (i.e. $C A D 2$ and $C A D 3$ ) are poorly or not expressed during lignification processes, thereby indicating probable different roles in other biological processes [40]. Phylogenetic analysis showed the relationship of two variants of $C A D$ proteins found in white teak,with other possible homologs; the CADs variant (putative CAD3) was tightly related with $S$. milthiorrhiza CAD, whereas CADL grouped together with CAD4 of $T$. grandis and CAD of $S$. indicum, indicating its possible relation with other members of the lamiales order. However, a more in-depth analysis is necessary to determine the specific identity, ortholog relationship, and biological function of all these members found in white teak. 
Differential expression analysis showed that a unique $H C T$ gene was significantly upregulated in white teak leaves. According to Besseau et al. [61], under certain conditions, HCT may have a key role in the synthesis of flavonoids which may be the case in the leaves of white teak. Xylem expression of HCT, although lower, could be enough to maintain the lignification process.

\section{Biosynthetic genes involved in non-lignin components of secondary cell wall}

Development of the xylem cells requires coordinated synthesis of the different elements constituting the secondary cell wall and programmed cell death. Some of the genes involved in these processes showed highly specific expression patterns. This is the case of IRX (Irregular xylem) genes, whose mutations affect the phenotypic development at the level of xylem cells [62] as well as PGSIP (plant glycogenin-like starch initiation proteins) genes, also known as Gux, that constitute a group of genes involved in xylan synthesis and whose function has been specifically related with secondary wall formation [63]. The IRXs genes are involved in synthesis of celluloses and hemicelluloses: IRX1, IRX3 and IRX5, for example, are cellulose synthases (CesA) specifically expressed in secondary cell wall [64]. Interestingly, key protease encoding genes such as $X C P 1, X C P 2$ and $V P E$, known to be involved in programmed cell death during xylem development, have been identified amongst xylem upregulated genes [65]. Furthermore, concomitant upregulation of genes encoding transcription factors like VNI2 and XND1, reported as specifically involved in the tight regulation of this process, has also been observed in our transcriptomic profile [11].

On the other hand, specific activation of laccase genes such as LAC4, LAC11, LAC17, LAC10 and LAC2, known to be involved in monolignol polymerization [66-68], may reflect the importance of these enzymes for xylem formation. Finally, upregulation of the FLA11 gene in xylem is in accordance with previous reports of its induction during the biosynthesis of the secondary cell wall in Arabidopsis and Eucalyptus, where a key role for these fasciclin-like arabinogalactan proteins in cell wall development biomechanics and development has been proposed [64].

Other key genes showed a different pattern of expression like those coding for cellulose synthases $(\operatorname{Ces} A)$, and cellulose synthase-like proteins $(C S L)$, for which a significant downregulation in stem was observed. This could be related to fluctuations in the expression of these genes according to the type of cell wall, and the developmental stage. In Arabidopsis for example, expression of CesA1, CesA2, CesA3, CesA5, CesA6 and CesA9 genes was shown to be related to formation of primary cell wall, rather than secondary cell wall [69]. In rice and
Eucalyptus camaldulensis, differences in the patterns of expression of some CesA were found in different types of tissue,cell wall or development stages [70, 71]. In the case of the CSL genes, in white teak most of them presented a predominant expression in leaves. About this, Lerouxel et al. [72], and Muthamilarasan et al. [73], indicate that these proteins have a relevant role in the synthesis of polysaccharides that are not necessarily part of the secondary cell wall hemicellulose matrix, and that environmental factors may affect their expression patterns.

Thus, xylem differentially expressed genes bring molecular knowledge on key functional and anatomical processes seemingly important for white teak's secondary xylem development, like the activation of programmed cell death, the activation of biosynthetic pathways related to lignin formation and other components of the secondary cell wall, or other associated regulatory processes.

\section{Conclusions}

Transcriptomic profiling of leaves and wood of young white teak (G. arborea Roxb.) trees was carried out, which constitutes an important genomic resource for this tropical timber. Differential expression analysis allowed to identify, for the first time in this species, major genes related with lignin biosynthesis and other components of the secondary cell wall, as well as the main transcription factors implicated in its regulation. Also, a catalog of intragenic microsatellite markers was obtained that may be useful in the future establishment of strategies for marker assisted selection of traits related with lignin formation, wood and/or secondary cell wall development in this economically important tree species. The transcriptome obtained could contribute significantly to increase the knowledge on wood and lignin formation that is still scarce in white teak, and will be highly useful for other non-model tropical wood tree species.

\section{Methods}

\section{Plant material and RNA isolation}

Plant material was obtained from approximately oneyear-old trees, located in the commercial plantation "El Neme", located at Coello (Tolima, Colombia). Leaves and stem cuttings from six different individual plants were collected and stored in liquid nitrogen. For RNA isolation from stem (with secondary xylem), external tissues that constitute the bark (phloem and periderm), and pith were removed from stems. Wood was chopped into small pieces using a sterile scalpel and grounded in liquid nitrogen. Total RNA was obtained using the protocol developed for RNA extraction from the pine wood by Chang et al. [74]. The leaf RNA was isolated 
using the Isolate I RNA isolation kit (Bioline, BIO52040). RNA samples were quantified using a Nanodrop spectrophotometer (2000, Thermo Scientific, USA) and its integrity was verified using $1 \%$ agarose gel electrophoresis in denaturing conditions.

\section{Library preparation and RNA-seq}

RNA samples with best integrity and concentration values were further validated using a bioanalyzer (2100 Agilent, USA) and samples with a RIN value > 7 were selected for sequencing. Nine RNA samples of each, xylem and leaves, were used to make 3 pools of 3 different individuals for each tissue type. From each pool of RNA, sequencing libraries were generated using the TruSeq library prep kit (Illumina, catalog no. RS-122-210, USA), obtaining six indexed libraries with three replicates for each tissue. All the libraries were sequenced using the NextSeq500 platform (Illumina, USA) to generate pairedend reads of $2 \times 150$ bases length.

\section{Bioinformatic analysis and de novo assembly of reference transcriptomes}

Raw RNA-seq reads were evaluated for quality, and sequences with a $\mathrm{Q}$ score $<20$ were eliminated. Adapters were eliminated by trimming the $10 \mathrm{bp}$ from the $5^{\prime}$ ends of the reads using Trimmomatic (version 0.36) [75]. Additionally, the reads corresponding to rRNAs were aligned and eliminated using the program bowtie2 (version 2.3.5) [76] and the SILVA database [77]. Finally, overrepresented sequences identified as contaminants or low complexity sequences were also eliminated from the further processing.

A de novo transcriptome assembly strategy was chosen discarding the alternative of reference genome-guided assembly, because the most closely related genome sequence available belongs to a relatively distant member of the Lamiaceae family, and a different genus ( $T$. grandis). Thus, transcriptome assembly was performed using Trinity (version 2.1.1) [78], setting as parameters a minimum length of 200 bases and a k-mer value of 25 . To obtain the transcriptome of secondary xylem, only the reads from stem were used in the assembly process. Additionally, filtered reads from xylem (stem) and leaves were pooled and assembled to obtain a combined reference transcriptome for the differential expression analysis. All the necessary softwares for the computational analysis were run using the High-Performance Computational Center (HPCC) at Texas Tech University and the ZINE Cluster of Xavierian University.

\section{Transcriptome annotation}

Transcriptome annotation was performed using the BLASTX similarity search program [79] against different public databases (TAIR10, NR, and UNIPROT/
SWISSPROT) and employing an e-value of $1 e-5$ as cutoff value. Categories of gene ontology (GO) were assigned using the GO annotation tool in TAIR [80]. For visualization of $\mathrm{GO}$ categories, the system of classification of Wego was used [81]. TAIR annotation was also used for the identification of transcription factors using the AGRIS transcription factors database [82]. KO identifiers necessary for the annotation in KEGG pathways were obtained using the Uniprot tools [83]. PFAM domains were identified using HMMER tools [84]. Additionally, the TRAPID tool was used to perform a quick annotation based in RAPSearch and identify ORFs in the transcripts [85]. For the validation of the identity of some genes with full length ORFs, a multiple alignment-based phylogenetic analysis of their derived protein sequences was performed with selected homologous sequences of plant model and tree species obtained from gene bank, Uniprot, TAIR, PlantTFDB and iTAK plant transcription factor database, using the MEGA 7 software [86].

\section{SSRs identification}

The xylem reference transcriptome was further analyzed for the presence of microsatellite markers using the MISA tool [87], considering a minimum of 5 motif repetition for the dinucleotides (DNRs), trinucleotides (TNRs), tretranucleotides (TtNRs), pentanucleotides (PNRs) and hexanucleotides (HNRs).

\section{Differential expression analysis}

For differential expression analysis, the transcriptome obtained from the assembly of pooled reads from xylem (stem) and leaf tissues was used as the reference transcriptome. Reads from each replicate and tissue were aligned against this reference transcriptome using bowtie2 and samtools [88] and the counts of the mapped sequences were obtained using bedtools [89]. Counts were normalized to FPKMs (Fragments Per Kilobase per Million mapped reads) and the differential expression analysis was performed using DESeq package [90] with the leaf transcripts used as control tissue. A principal component analysis (PCA) of expression levels and using transcripts counts was performed to assess the variance in transcript profiling simultaneously amongst samples (replicates) and treatments (i.e. tissues: xylem and leaves). PCA plot was obtained using ggplot2 $\mathrm{R}$ package [91].

Selection of differentially expressed genes between xylem and leaf tissue was done using a binomial test with an adjusted $p$-value $(p<0.05)$ and values of logarithmic to base 2 of expression fold change $\left(\log _{2} \mathrm{FC}\right) \geq 2$ or $\leq-2$, indicating up- or down-regulation of the xylem genes in comparison with leaves. The functional annotation of differentially expressed transcripts was performed 
using the Mercator [92] and TRAPID [85] tools. Visualization of the key metabolic pathways with differentially expressed genes was performed using the MapMan program [93].

\section{Differential expression validation of genes using RT-qPCR}

To validate the differential expression of a selection of genes upregulated in xylem, RT-qPCR was performed. cDNA of xylem (stem) and leaves were prepared using the Transcriptor first strand cDNA synthesis kit (Roche, USA): $1 \mu$ g of total RNA per $40 \mu$ final reaction volume was used following manufacturer operating procedure. Primers were designed for the selected 13 candidate genes related to the monolignol biosynthetic pathway, cellulose and hemicellulose synthesis, and transcription factors involved in the regulation of secondary cell wall biosynthesis. UBIQUITIN5 (UBQ5), $\beta$-TUBULIN ( $\beta$-TUB) and HISTONE3 (HIS3) genes were evaluated as reference genes based on the transcriptome data and finally UBIQUITIN5 (UBQ5) was used for the normalization of RT-qPCR data. Primer3 tool was used for the primer designing taking into account the criteria for qPCR primers [94] (Supplementary Table 3).

RT-qPCR was run in a Lightcycler 96 real time PCR (Roche, USA) using the Fast start ${ }^{\mathrm{m} \text { th }}$ SYBR green (Roche, USA in a 96-well plate with 3 biological replicates and 3 technical replicates for each gene. Reactions were performed by manufacturer operating procedure in a final volume of $20 \mu \mathrm{l}$ with $10 \mu \mathrm{l}$ of SYBR mix, $5 \mu \mathrm{l}$ of five-fold diluted cDNA (equivalent to $25 \mathrm{ng}$ of reverse transcribed total RNA) and primers at a final concentration of 0.5 $\mathrm{pmol} / \mu \mathrm{l}$. Three negative template controls per primer pair were included in each plate. Running conditions were: a pre incubation phase at $95^{\circ} \mathrm{C}$ for $10 \mathrm{~min}, 45$ cycles of amplification with 3 steps: $95^{\circ} \mathrm{C}$ for $10 \mathrm{~s}, 58^{\circ} \mathrm{C}$ for $10 \mathrm{~s}$ and $72{ }^{\circ} \mathrm{C}$ for $10 \mathrm{~s}$, a melting phase with 3 steps: $95^{\circ} \mathrm{C}$ for $10 \mathrm{~s}, 65^{\circ} \mathrm{C}$ for $60 \mathrm{~s}$ and $97^{\circ} \mathrm{C}$ for $1 \mathrm{~s}$, finally a cooling phase at $37^{\circ} \mathrm{C}$ for $30 \mathrm{~s}$. Melting curves were analyzed to verify the presence of only one product and the absence of primer dimers. The $\Delta \Delta \mathrm{Ct}$ comparative method [95] was used for the estimation of the change of gene expression between the two tissues.

\footnotetext{
Abbreviations

CAD: cinnamyl alcohol dehydrogenase; CRISPR-CAS: Clustered Regularly Interspaced Short Palindromic Repeats- CRISPR Associated Nuclease; GO: gene ontology; PAL: Phenylalanine ammonia-lyase; $\mathrm{C} 4 \mathrm{H}$ : trans-cinnamate 4-hydroxylase; 4CL: 4-coumarate-CoA ligase; HCT: p-hydroxy-cinnamoyl-CoA; CCOAOMT: caffeoyl-COA O-methyltransferase; CCR: hydroxycinnamoyl-CoA reductase; $\mathrm{F} 5 \mathrm{H}$ : ferulate 5 -hydroxylase; COMT: caffeic acid $\mathrm{O}$ methyltransferase; SSR: Single Sequence Repeat; KEGG: Kyoto encyclopedia of genes and genomes; ORF: open reading frame; FPKMs: Fragments per kilobase per million mapped reads; PCA: principal component analysis; $\log _{2}$ FC: $\log _{2}$ (fold change); DEGs: Differentially expressed genes; RTQPCR: quantitative reverse transcription PCR; IRX: Irregular xylem; CesA: cellulose synthase; PGSIP: plant glycogenin-like starch initiation proteins; CSL: cellulose synthase-like protein
}

\section{Supplementary Information}

The online version contains supplementary material available at https://doi. org/10.1186/s12864-021-07777-x.

Additional file 1: Supplementary Fig. 1. Principal component analysis (PCA) of G. arborea expressed transcripts. Transcript read counts obtained in each sample were used. Difference between plant tissues (condition) is highlighted.

Additional file 2: Supplementary Fig. 2. Main functional categories represented by DEG.

Additional file 3: Supplementary Table 1. Summary of G. arborea de novo transcriptome assembly metrics combining RNA-seq data from leaves and xylem.

Additional file 4: Supplementary Table 2. Frequency in the number of repetitions found for SSRs microsatellite markers.

Additional file 5: Supplementary Table 3. Primers used for RT-qPCR validation of differentially expressed genes between xylem and leaf tissues.

\section{Acknowledgements}

We thank Suzen, "el mono" and Felipe Ballesteros, owners of "El Neme" forest plantation at Coello (Tolima), for allowing sampling of white teak trees, and Juliana Vásquez Ardila for her kind assistance during field sampling.

\section{Authors' contributions}

MLYL and WT conceived and designed RNA-seq experiments. MLYL carried out all experimental and bioinformatic work and drafted first versions of the manuscript. KMR and VKB assisted on bioinformatic analysis and RT-qPCR validation respectively, and both assisted on manuscript preparation. WT supervised RNA-seq experimental work. LD an VM participated in experimental designing and supervision of bioinformatic, RT-qPCR and statistical analysis and contributed to the discussion of overall results. All coauthors participated in the manuscript writing and revision. WT revised final version of manuscript for submission. All authors read and approved the final manuscript.

\section{Funding}

This work was supported by the Pontifical Xavierian University research grant 00565; MLYL was a recipient of a graduate studies fellowship from

Colciencias.

\section{Availability of data and materials}

Sequences for comparative phylogenetic analysis were downloaded from Uniprot (https://www.uniprot.org/), NCBI protein (https://www.ncbi.nlm.nih. gov/protein/), TAIR (https://www.arabidopsis.org), PlantTFDB (http://planttfdb. gao-lab.org/) or iTAK (http://itak.feilab.net/cgi-bin/itak/index.cgi) databases. Accession numbers of all downloaded sequences employed for multiple alignments and phylogenetic analyses are listed in Fig. 3 and Fig. 9 legends. All assembled sequences of this transcriptomic resource have been deposited in the European Nucleotide Archives (ENA) public database under the following accession numbers: PRJEB36634 (ERP119847).

The data supporting the conclusions of this article are included within the article and its supplementary information files.

\section{Declarations}

\section{Ethics approval and consent to participate}

Field sampling of plant material was carried out in a small commercial plantation with the proper verbal authorization and informed consent of the owners, who judged unnecessary any other written consent and participated in the sampling events as part of their own silvicultural management (thinning and pruning). This verbal consent was accepted by the research and ethical committee of the Department of Biology of the Pontifical Xavierian University because two members of the owner's family and two co-investigators of this research witnessed and endorsed the verbal agreement.

According to Colombian National Legislation, for non-native species field sampling, or sampling of non-wild species or commercial varieties within commercial plantations, the deposit of voucher specimen is not required [96]. 
Ethical compliance of this research was revised and approved by the research and ethical committee of the School of Sciences of Pontifical Xavierian University.

\section{Consent for publication}

Not applicable.

\section{Competing interests}

The authors declare that they have no competing interests.

\section{Author details}

'Department of Biology, Pontificia Universidad Javeriana, Carrera $7 \mathrm{~N}^{\circ}$ 43-82, Bogotá 110231, Colombia. ${ }^{2}$ Department of Plant and Soil Sciences, Fiber and Biopolymer Research Institute, Texas Tech University, Lubbock, TX 79409, USA. ${ }^{3}$ Department of Plant and Microbial Biology, College of Biological Sciences, University of Minnesota, Minneapolis, MN, USA. ${ }^{4}$ Environmental Molecular Sciences Laboratory, Pacific Northwest National Laboratory, Richland, WA, USA.

\section{Received: 10 November 2020 Accepted: 7 June 2021}

Published online: 02 July 2021

\section{References}

1. Hinchee M, Rottmann W, Mullinax L, Zhang C, Chang S, Cunningham M, et al. Short-rotation woody crops for bioenergy and biofuels applications. In Vitro Cell Dev Biol Plant. 2009;45(6):619-29. Epub 2009/11/26. https://doi. org/10.1007/s1 1627-009-9235-5. PubMed PMID: 19936031; PubMed Central PMCID: PMCPMC2778772.

2. Wang JP, Matthews ML, Williams $C M$, Shi R, Yang C, Tunlaya-anukit S, et al. Improving wood properties for wood utilization through multi-omics integration in lignin biosynthesis. Nat Commun. 2018;9(1579). https://doi. org/10.1038/s41467-018-03863-z.

3. Chanoca A, De Vries L, Boerjan W. Lignin engineering in Forest trees. Front Plant Sci. 2019;10. https://doi.org/10.3389/fpls.2019.00912.

4. Zhang G, Wang L, Li X, Bai S, Li Z, Yanting ST, et al. Distinctively altered lignin biosynthesis by site-modification of OsCAD2 for enhanced biomass saccharification in rice. GCB Bioenergy. 2020;13:305-19. https://doi.org/1 $0.1111 /$ gcbb.12772.

5. Gui J, Lam PY, Tobimatsu Y, Umezawa T, Li L. Fibre-specific regulation of lignin biosynthesis improves biomass quality in Populus. New Phytol. 2020 226:1074-87. https://doi.org/10.1111/nph.16411.

6. Dvorak WS. World view of Gmelina arborea : opportunities and challenges. New For. 2004;28(2/3):111-26. https://doi.org/10.1023/B:NEFO.0000040940.32 574.22 .

7. Roshetko J.M, Mulawarman, Purnomosidhi P. Gmelina arborea- a viable species for smallholder tree farming in Indonesia?. New For. 2004;28 207215. https://doi.org/10.1023/B:NEFO.0000040948.53797.c5, 2/3.

8. Onyekwelu JC. Managing short rotation tropical plantations as sustainable source of bioenergy. Silviculture Tropics Trop Forestry. 2011;8:109-17. https://doi.org/10.1007/978-3-642-19986-8_9.

9. Basumaraty S, Deka D, Deka DC. Composition of biodiesel from Gmelina arborea seed oil. Adv Appl Sci Res. 2012;3(5):2745-53.

10. Moya R, Tenorio C. Características de combustibilidad de diez especies de plantaciones de rápido crecimiento en Costa Rica. Rev For Mes Kurú. 2013 10(24):26-33. https://doi.org/10.18845/rfmk.v10i24.1321

11. Bollhoner B, Prestele J, Tuominen $\mathrm{H}$. Xylem cell death: emerging understanding of regulation and function. J Exp Bot 2012;63(3):1081-1094 Epub 2012/01/04. https://doi.org/10.1093/jxb/err438. PubMed PMID: 22213814.

12. Mendu V, Harman-Ware AE, Crocker M, Jae J, Stork J, Morton S, et al. Identification and thermochemical analysis of high-lignin feedstocks for biofuel and biochemical production. Biotechnol Biofuels. 2011;4(1):43. https://doi.org/10.1186/1754-6834-4-43.

13. Somerville C. Cellulose synthesis in higher plants. Ann Rev Cell Dev Biol 2006;22(1):53-78. https://doi.org/10.1146/annurev.cellbio.22.022206.160206. PubMed PMID: 16824006.

14. Ko JH, Kim WC, Han KH. Ectopic expression of MYB46 identifies transcriptional regulatory genes involved in secondary wall biosynthesis in Arabidopsis. Plant J 2009;60(4):649-665. Epub 2009/08/14. https://doi.org/1 0.1111/j.1365-313X.2009.03989.x . PubMed PMID: 19674407.
15. Zhong R, Ye ZH. Secondary cell walls: biosynthesis, patterned deposition and transcriptional regulation. Plant Cell Physiol 2015;56(2):195-214. Epub 2014/10/09. https://doi.org/10.1093/pcp/pcu140. PubMed PMID: 25294860

16. Silva-Moura JC, Bonine CA, de Oliveira Fernandes Viana J, Dornelas MC, Mazzafera P. abiotic and biotic stresses and changes in the lignin content and composition in plants. J Integr Plant Biol 2010;52(4):360-376. Epub 2010/04/10. https://doi.org/10.1111/j.1744-7909.2010.00892.x. PubMed PMID: 20377698.

17. Vogt T. Phenylpropanoid biosynthesis. Mol Plant 2010;3(1):2-20. Epub 2009/ 12/26. https://doi.org/10.1093/mp/ssp106. PubMed PMID: 20035037.

18. Fraser CM, Chapple C. The phenylpropanoid pathway in Arabidopsis. Arabidopsis Book. 2011;9:e0152. Epub 2012/02/04. https://doi.org/10.1199/ta b.0152. PubMed PMID: 22303276; PubMed Central PMCID: PMCP MC3268504.

19. Vanholme R, Demedts B, Morreel K, Ralph J, Boerjan W. Lignin biosynthesis and structure. Plant Physiol. 2010;153(3):895-905. https://doi.org/10.1104/ pp.110.155119.

20. Guillaumie S, Mzid R, Mechin V, Leon C, Hichri I, Destrac-Irvine A, et al. The grapevine transcription factor WRKY2 influences the lignin pathway and xylem development in tobacco. Plant Mol Biol 2010;72(1-2):215-234. Epub 2009/11/11. https://doi.org/10.1007/s11103-009-9563-1. PubMed PMID: 19902151.

21. Weng JK, Chapple C. The origin and evolution of lignin biosynthesis. New Phytol 2010;187(2):273-285. Epub 2010/07/21. https://doi.org/10.1111/j.14698137.2010.03327.x. PubMed PMID: 20642725.

22. Xie M, Zhang J, Tschaplinski TJ, Tuskan GA, Chen J-G, Muchero W. Regulation of Lignin Biosynthesis and Its Role in Growth-Defense Tradeoffs. Front Plant Sci. 2018:9(1427). https://doi.org/10.3389/fpls.2018.01427.

23. Zhong $\mathrm{R}$, Ye Z-H. Transcriptional regulation of lignin biosynthesis. Plant Signal Behav 2009:4(11):1028-1034. https://doi.org/10.4161/psb.4.11.9875. PubMed PMID: 19838072.

24. Zhao Q, Dixon RA. Transcriptional networks for lignin biosynthesis: more complex than we thought? Trends Plant Sci 2011;16(4):227-233. Epub 2011/ 01/14. https://doi.org/10.1016/.tplants.2010.12.005. PubMed PMID: 21227733.

25. Liu J, Osbourn A, Ma P. MYB transcription factors as regulators of Phenylpropanoid metabolism in plants. Mol Plant 2015;8(5):689-708. Epub 2015/04/04. https://doi.org/10.1016/j.molp.2015.03.012. PubMed PMID: 25840349.

26. Van Acker R, Vanholme R, Storme V, Mortimer JC, Dupree P. Lignin biosynthesis perturbations affect secondary cell wall composition and saccharification yield in Arabidopsis thaliana. Biotechnol Biofuels. 2013;6(1): 1-17. https://doi.org/10.1186/1754-6834-6-46.

27. Zhang J, Tuskan GA, Tschaplinski TJ, Muchero W, Chen J-G. Transcriptional and Post-transcriptional Regulation of Lignin Biosynthesis Pathway Genes in Populus. Front Plant Sci. 2020;11 May:1-11. https://doi.org/10.3389/fpls.2020. 00652.

28. Li X, Weng JK, Chapple C. Improvement of biomass through lignin modification. Plant J 2008:54(4):569-581. Epub 2008/05/15. https://doi.org/1 0.1111/j.1365-313X.2008.03457.x. PubMed PMID: 18476864.

29. Wang $H$, Xue $Y$, Chen $Y$, Li R, Wei J. Lignin modification improves the biofuel production potential in transgenic Populus tomentosa. Ind Crop Prod. 2012;37(1):170-7. . https://doi.org/10.1016/j.indcrop.2011.12.014.

30. Ziebell A, Gjersing E, Hinchee M, Katahira R, Sykes RW, Johnson DK, et al. Downregulation of $\mathrm{p}$-Coumaroyl Quinate/shikimate 3'-hydroxylase $\left(\mathrm{C} 3^{\prime} \mathrm{H}\right)$ or Cinnamate-4-hydrolylase $(\mathrm{C} 4 \mathrm{H})$ in Eucalyptus urophylla $\times$ Eucalyptus grandis leads to increased extractability. BioEnergy Res. 2016;9(2):691-9. https://doi. org/10.1007/s12155-016-9713-7.

31. Rojas A, Moreno L, Melgarejo LM, Rodríguez M. Physiological response of gmelina (Gmelina arborea Roxb) to hydric conditions of the colombian Caribbean. Agronomía colombiana. 2012;30(1):52-8.

32. Malavasi UC, Davis AS, Malavasi MDM. Lignin in Woody plants under water stress : a review. Floresta e Ambient. 2016;23(4):589-97. https://doi.org/10.1 590/2179-8087.143715

33. Pappas M, Pappas GJ, Grattapaglia D. Genome-wide discovery and validation of Eucalyptus small RNAs reveals variable patterns of conservation and diversity across species of Myrtaceae. BMC Genomics. 2015;16:1113. Epub 2015/12/31. https://doi.org/10.1186/s12864-015-2322-6. PubMed PMID: 26714854; PubMed Central PMCID: PMCPMC4696225.

34. Hefer CA, Mizrachi E, Myburg AA, Douglas CJ, Mansfield SD. Comparative interrogation of the developing xylem transcriptomes of two wood-forming 
species: Populus trichocarpa and Eucalyptus grandis. New Phytol 2015; 206(4):1391-1405. Epub 2015/02/11. https://doi.org/10.1111/nph.13277. PubMed PMID: 25659405.

35. Li X, Wu HX, Southerton SG. Seasonal reorganization of the xylem transcriptome at different tree ages reveals novel insights into wood formation in Pinus radiata. New Phytol 2010;187(3):764-776. Epub 2010/06/ 22. https://doi.org/10.1111/j.1469-8137.2010.03333.x. PubMed PMID: 20561208.

36. Wong MM, Cannon $\mathrm{CH}$, Wickneswari R. Identification of lignin genes and regulatory sequences involved in secondary cell wall formation in Acacia auriculiformis and Acacia mangium via de novo transcriptome sequencing. BMC Genomics. 2011;12:342. Epub 2011/07/07. https://doi.org/10.1186/14 71-2164-12-342. PubMed PMID: 21729267; PubMed Central PMCID: PMCP MC3161972

37. Galeano E, Vasconcelos TS, Vidal M, Mejia-Guerra MK, Carrer H. Large-scale transcriptional profiling of lignified tissues in Tectona grandis. BMC Plant Biol. 2015;15:221. Epub 2015/09/16. https://doi.org/10.1186/s12870-0150599-x. PubMed PMID: 26369560; PubMed Central PMCID: PMCP MC4570228.

38. Yasodha R, Vasudeva R, Balakrishnan S, Sakthi AR, Abel N, Binai N, Rajashekar B, Bachpai VKW, Pillai C, Dev SA Draft genome of a high value tropical timber tree, Teak ( Tectona grandis L . f ): insights into SSR diversity, phylogeny and conservation. DNA Res 2018;25:409-419. https://doi.org/10.1 093/dnares/dsy013.

39. Zhao D, Hamilton JP, Bhat WW, Johnson R, Godden GT, Kinser TJ, et al. A chromosomal-scale genome assembly of Tectona grandis reveals the importance of tandem gene duplication and enables discovery of genes in natural product biosynthetic pathways. Gigascience. 2019;8(3):1-10. . https:// doi.org/10.1093/gigascience/giz005.

40. Yoon J, Choi H, An G. Roles of lignin biosynthesis and regulatory genes in plant development. J Integr Plant Biol. 2015;57(11):902-12. Epub 2015/08/ 25. https://doi.org/10.1111/jipb.12422. PubMed PMID: 26297385; PubMed Central PMCID: PMCPMC5111759.

41. Ranade S, Lin Y, Zuccolo A, Van de Peer Y, García-Gil M. Comparative in silico analysis of EST-SSR in angiosperm and gymnosperm tree genera. BMC Plant Biol. 2014;14(220):1-10.

42. Sonah H, Deshmukh RK, Sharma A, Singh VP, Gupta DK, Gacche RN, et al. Genome-wide distribution and organization of microsatellites in plants: an insight into marker development in Brachypodium. PLoS One. 2011;6(6): e21298. Epub 2011/06/30. https://doi.org/10.1371/journal.pone.0021298. PubMed PMID: 21713003; PubMed Central PMCID: PMCPMC3119692.

43. Zhang L, Zuo K, Zhang F, Cao Y, Wang J, Zhang Y, et al. Conservation of noncoding microsatellites in plants: implication for gene regulation. BMC Genomics. 2006;7:323. Epub 2006/12/26. https://doi.org/10.1186/1471-21647-323. PubMed PMID: 17187690; PubMed Central PMCID: PMCPMC1781443.

44. Wu G, Lin W, Huang T, Poethig S, Springer P, Kerstetter RA. KANADI1 regulates adaxial-abaxial polarity in Arabidopsis by directly repressing the transcription of assymetric leaves2. PNAS. 2008;105(42):16392-7. https://doi. org/10.1073/pnas.0803997105.

45. Zhang X, Ju HW, Chung MS, Huang P, Ahn SJ, Kim CS. The R-R-type MYBlike transcription factor, AtMYBL, is involved in promoting leaf senescence and modulates an abiotic stress response in Arabidopsis. Plant Cell Physiol. 2011;52(1):138-148. Epub 2010/11/26. https://doi.org/10.1093/pcp/pcq180. PubMed PMID: 21097474.

46. Song Y, Yang C, Gao S, Zhang W, Li L, Kuai B. Age-triggered and darkinduced leaf senescence require the bHLH transcription factors PIF3, 4, and 5. Mol Plant. 2014;7(12):1776-87. Epub 2014/10/10. . https://doi.org/10.1093/ $\mathrm{mp} / \mathrm{ssu} 109$.

47. Muthamilarasan M, Bonthala VS, Mishra AK, Khandelwal R, Khan Y, Roy R, Prasad M. C2H2 type of zinc finger transcription factors in foxtail millet define response to abiotic stresses. Funct Integr Genomics 2014;14(3):531543. https://doi.org/10.1007/s10142-014-0383-2. Epub 2014 Jun 11. PMID: 24915771.

48. Jiang AL, Xu ZS, Zhao GY., Cui XY, Chen M, Li LC, Ma YZ Genome-wide analysis of the $\mathrm{C} 3 \mathrm{H}$ zinc finger transcription factor family and drought responses of members in Aegilops tauschii . Plant Mol Biol Rep. 2014;32: 1241-1256. 10.1007/s11105-014-0719-z, 6.

49. Ambawat S, Sharma P, Yadav NR, Yadav RC. MYB transcription factor genes as regulators for plant responses: an overview. Physiol Mol Biol Plants. 2013; 19(3):307-21. Epub 2014/01/17. https://doi.org/10.1007/s12298-013-0179-1. PubMed PMID: 24431500; PubMed Central PMCID: PMCPMC3715649.
50. Nuruzzaman M, Sharoni AM, Kikuchi S. Roles of NAC transcription factors in the regulation of biotic and abiotic stress responses in plants. Front Microbiol. 2013;4:248. Epub 2013/09/24. https://doi.org/10.3389/fmicb.2013. 00248. PubMed PMID: 24058359; PubMed Central PMCID: PMCPMC3759801.

51. Nakano Y, Yamaguchi M, Endo H, Rejab NA, Ohtani M. NAC-MYB-based transcriptional regulation of secondary cell wall biosynthesis in land plants. Front Plant Sci. 2015;6:288. Epub 2015/05/23. https://doi.org/10.3389/fpls.201 5.00288. PubMed PMID: 25999964; PubMed Central PMCID: PMCP MC4419676.

52. Hussey SG, Mizrachi E, Creux NM, Myburg AA. Navigating the transcriptional roadmap regulating plant secondary cell wall deposition. Front Plant Sci. 2013;4:325. Epub 2013/09/07. https://doi.org/10.3389/fpls.2013.00325. PubMed PMID: 24009617; PubMed Central PMCID: PMCPMC3756741.

53. Yang JH, Wang H. Molecular Mechanisms for Vascular Development and Secondary Cell Wall Formation. Front Plant Sci. 2016;7:356. Epub 2016/04/ 06. https://doi.org/10.3389/fpls.2016.00356. PubMed PMID: 27047525; PubMed Central PMCID: PMCPMC4801872.

54. Mitsuda N, Iwase A, Yamamoto H, Yoshida M, Seki M, Shinozaki K, et al. NAC transcription factors, NST1 and NST3, are key regulators of the formation of secondary walls in woody tissues of Arabidopsis. Plant Cell. 2007;19(1):27080. Epub 2007/01/24. https://doi.org/10.1105/tpc.106.047043. PubMed PMID: 17237351; PubMed Central PMCID: PMCPMC1820955.

55. Saito K, Yonekura-Sakakibara K, Nakabayashi R, Higashi Y, Yamazaki M, Tohge T, Fernie AR The flavonoid biosynthetic pathway in Arabidopsis: structural and genetic diversity. Plant Physiol Biochem 2013;72:21-34. Epub 2013/03/12. https://doi.org/10.1016/j.plaphy.2013.02.001. PubMed PMID: 23473981.

56. Hirano K, Aya K, Kondo M, Okuno A, Morinaka Y, Matsuoka M. OsCAD2 is the major CAD gene responsible for monolignol biosynthesis in rice culm. Plant Cell Rep. 2011;31(1):91-101. . https://doi.org/10.1007/s00299-011-11427.

57. Shen $H$, Mazarei M, Hisano H, Escamilla-Trevino L, Fu C, Pu Y, et al. A genomics approach to deciphering lignin biosynthesis in switchgrass. Plant Cell. 2013;25(11):4342-61. Epub 2013/11/29. https://doi.org/10.1105/ tpc.113.118828. PubMed PMID: 24285795; PubMed Central PMCID: PMCP MC3875722.

58. Raes J, Rohde A, Christensen JH, Van de Peer Y, Boerjan W. Genome-wide characterization of the lignification toolbox in Arabidopsis. Plant Physiol. 2003;133(3):1051-71. Epub 2003/11/13. https://doi.org/10.1104/pp.103.0264 84. PubMed PMID: 14612585; PubMed Central PMCID: PMCPMC523881.

59. Bethke G, Pecher P, Eschen-Lippold K, Katagiri F. Activation of the Arabidopsis thaliana mitogen-actived protein kinase MPK11 by the felagellin-derived elicitor peptide, flg22. MPMI. 2012;25(4):471-80. https:// doi.org/10.1094/MPMl-11-11-0281.

60. Cheng X, Li M, Li D, Zhang J, Jin Q, Sheng L, et al. Characterization and analysis of CCR and CAD gene families at the whole-genome level for lignin synthesis of stone cells in pear (Pyrus bretschneideri) fruit. Biol Open. 2017;6(11):1602-13. Epub 2017/11/17. https://doi.org/10.1242/bio. 026997. PubMed PMID: 29141952; PubMed Central PMCID: PMCP MC5703608.

61. Besseau S, Hoffmann L, Geoffroy P, Lapierre C, Pollet B, Legrand M. Flavonoid accumulation in Arabidopsis repressed in lignin synthesis affects auxin transport and plant growth. Plant Cell. 2007;19(1):148-62. Epub 2007/ 01/24. https://doi.org/10.1105/tpc.106.044495. PubMed PMID: 17237352; PubMed Central PMCID: PMCPMC1820963.

62. Carpita NC, McCann MC. Characterizing visible and invisible cell wall mutant phenotypes. J Exp Bot 2015;66(14):4145-4163. Epub 2015/04/16. https://doi. org/10.1093/jxb/erv090. PubMed PMID: 25873661.

63. Rennie EA, Hansen SF, Baidoo EE, Hadi MZ, Keasling JD, Scheller HV. Three members of the Arabidopsis glycosyltransferase family 8 are xylan glucuronosyltransferases. Plant Physiol. 2012;159(4):1408-17. Epub 2012/06/ 19. https://doi.org/10.1104/pp.112.200964. PubMed PMID: 22706449; PubMed Central PMCID: PMCPMC3428776.

64. MacMillan CP, Mansfield SD, Stachurski ZH, Evans R, Southerton SG. Fasciclin-like arabinogalactan proteins: specialization for stem biomechanics and cell wall architecture in Arabidopsis and Eucalyptus. Plant J. 2010;62(4): 689-703. https://doi.org/10.1111/j.1365-313X.2010.04181.x.

65. Zamyatnin AA. Plant proteases involved in regulated cell death. Usp Biol Khim. 2015;80(13):1701-15. https://doi.org/10.1134/S0006297915130064.

66. Wang J, Feng J, Jia W, Chang S, Li S, Li Y. Lignin engineering through laccase modification : a promising field for energy plant improvement. 
Biotechnol Biofuels. 2015;8(1):1-11. https://doi.org/10.1186/s13068-0150331-y.

67. Berthet S, Demont-Caulet N, Pollet B, Bidzinski P, Cezard L, Le Bris P, et al. Disruption of LACCASE4 and 17 results in tissue-specific alterations to lignification of Arabidopsis thaliana stems. Plant Cell. 2011;23(3):1124-37. Epub 2011/03/31. https://doi.org/10.1105/tpc.110.082792. PubMed PMID: 21447792; PubMed Central PMCID: PMCPMC3082258.

68. Zhao Q, Nakashima J, Chen F, Yin Y, Fu C, Yun J, et al. Laccase is necessary and nonredundant with peroxidase for lignin polymerization during vascular development in Arabidopsis. Plant Cell. 2013;25(10):3976-87. Epub 2013/10/22. https://doi.org/10.1105/tpc.113.117770. PubMed PMID: 24143805; PubMed Central PMCID: PMCPMC3877815. 4143805; PubMed Central PMCID: PMCPMC3877815.

69. Endler A, Persson S. Cellulose synthases and synthesis in Arabidopsis. Mol Plant 2011;4(2):199-211. Epub 2011/02/11. https://doi.org/10.1093/mp/ ssq079. PubMed PMID: 21307367.

70. Wang L, Guo K, Li Y, Tu Y, Hu H, Wang B, et al. Expression profiling and integrative analysis of the CESA/CSL superfamily in rice. BMC Plant Biol. 2010;10(282):1-16.

71. Lin Y, Kao Y-Y, Chen Z-Z, Chu F-H, Chung J-D. cDNA cloning and molecular characterization of five cellulose synthase a genes from Eucalyptus camaldulensis. J Plant Biochem Biot. 2013;23(2):199-210. https://doi.org/10.1 007/s13562-013-0202-1.

72. Lerouxel O, Cavalier DM, Liepman AH, Keegstra K. Biosynthesis of plant cell wall polysaccharides - a complex process. Curr Opin Plant Biol 2006;9(6): 621-630. Epub 2006/10/03. https://doi.org/10.1016/j.pbi.2006.09.009. PubMed PMID: 17011813.

73. Muthamilarasan M, Khan Y, Jaishankar J, Shweta S, Lata C, Prasad M. Integrative analysis and expression profiling of secondary cell wall genes in C4 biofuel model Setaria italica reveals targets for lignocellulose bioengineering. Front Plant Sci. 2015;6:965. Epub 2015/11/20. https://doi. org/10.3389/fpls.2015.00965. PubMed PMID: 26583030; PubMed Central PMCID: PMCPMC4631826.

74. Chang S, Puryear J, Cairney J. A simple and efficient method for isolating RNA from pine trees. Plant Mol Biol Rep. 1993;11(2):113-6. . https://doi.org/1 0.1007/bf02670468.

75. Bolger AM, Lohse M, Usadel B. Trimmomatic: a flexible trimmer for Illumina sequence data. Bioinformatics. 2014;30(15):2114-20. Epub 2014/04/04. https://doi.org/10.1093/bioinformatics/btu170. PubMed PMID: 24695404; PubMed Central PMCID: PMCPMC4103590.

76. Langmead B, Salzberg SL. Fast gapped-read alignment with Bowtie 2. Nat Methods. 2012;9(4):357-9. Epub 2012/03/06. https://doi.org/10.1038/ nmeth.1923. PubMed PMID: 22388286; PubMed Central PMCID: PMCP MC3322381.

77. Quast C, Pruesse E, Yilmaz P, Gerken J, Schweer T, Yarza P, et al. The SILVA ribosomal RNA gene database project: improved data processing and webbased tools. Nucleic Acids Res. 2013;41(Database issue):D590-6. Epub 2012/ 11/30. https://doi.org/10.1093/nar/gks1219. PubMed PMID: 23193283; PubMed Central PMCID: PMCPMC3531112.

78. Grabherr M, Haas B, Yassour M, Levin J, Thompson D, Amit I, et al. Trinity: reconstructing a full length transcriptome without a genome from RNA-Seq data. Nat Biotechnol. 2013;29(7):644-52. https://doi.org/10.1038/nbt.1883. Trinity.

79. Altschul SF, Gish W, Miller W, Myers EW, Lipman DJ. Basic local alignment search tool. J Mol Biol 1990;215(3):403-410. Epub 1990/10/05. https://doi. org/10.1016/s0022-2836(05)80360-2. PubMed PMID: 2231712.

80. Doyle A, Garcia-Hernandez M, Huala E, Lander G, Montoya M, Miller N, et al. The Arabidopsis information resource (TAIR): a model organism database providing a centralized, curated gateway to Arabidopsis biology, research materials and community. Nucleic Acids Res. 2003;31(1):224-8. https://doi. org/10.1093/nar/gkg076.

81. Ye J, Fang L, Zheng H, Zhang Y, Chen J, Zhang Z, et al. WEGO: a web tool for plotting GO annotations. Nucl Acids Res. 2006;34(Web Server):W293-W7. https://doi.org/10.1093/nar/gkl031.

82. Palaniswamy SK, James S, Sun H, Lamb RS, Davuluri RV, Grotewold E. AGRIS and AtRegNet. a platform to link cis-regulatory elements and transcription factors into regulatory networks. Plant Physiol. 2006;140(3):818-29. Epub 2006/03/10. https://doi.org/10.1104/pp.105.072280. PubMed PMID: 16524982; PubMed Central PMCID: PMCPMC1400579.

83. The UniProt Consortium. UniProt: the universal protein knowledgebase. Nucl Acids Res. 2017;45(D1):D158-69. https://doi.org/10.1093/nar/gkw1099.
84. Finn RD, Clements J, Eddy SR. HMMER web server: interactive sequence similarity searching. Nucl Acids Res. 2011;39(Web Server issue):W29-W37. https://doi.org/10.1093/nar/gkr367.

85. Van Bel M, Proost S, Neste CV, Deforce D, Van De Peer Y, Vandepoele K. TRAPID : an efficient online tool for the functional and comparative analysis of de novo RNA-Seq transcriptomes. Genome Biol. 2013;14:1-10.

86. Kumar S, Stecher G, Tamura K. MEGA7: molecular evolutionary genetics analysis version 7.0 for bigger datasets. Mol Biol Evol. 2016;33(7):1870-4. https://doi.org/10.1093/molbev/msw054.

87. Thiel T, Michalek W, Varshney K, Graner A. Exploiting EST databases for the development and characterization of gene-derived SSR-markers in barley (Hordeum vulgare L.). Theor Appl Genet. 2003;106:411-22. https://doi.org/1 0.1007/s00122-002-1031-0.

88. Li H, Handsaker B, Wysoker A, Fennell T, Ruan J, Homer N, et al. The sequence alignment / map format and SAMtools. Bioinformatics. 2009; 25(16):2078-9. https://doi.org/10.1093/bioinformatics/btp352.

89. Quinlan AR, Hall IM. BEDTools : a flexible suite of utilities for comparing genomic features. Bioinformatics. 2010;26(6):841-2. https://doi.org/10.1093/ bioinformatics/btq033.

90. Anders S, Huber W. Differential expression analysis for sequence count data. Genome Biol. 2010;11(R106):1-12.

91. Wickham H. Ggplot2: elegant graphics for data analysis. 2nd ed. New York: Springer; 2009. https://doi.org/10.1007/978-0-387-98141-3.

92. Lohse M, Nagel A, Herter T, May P, Schroda M, Zrenner R, et al. Mercator : a fast and simple web server for genome scale functional annotation of plant sequence data. Plant Cell Environ. 2014:37(5):1250-8. https://doi.org/1 $0.1111 /$ pce.12231.

93. Thimm O, Blasing O, Gibon Y, Nagel A, Meyer S, Kru P, et al. MAPMAN : a user-driven tool to display genomics data sets onto diagrams of metabolic pathways and other biological processes. Plant J. 2004;37:914-39. https:// doi.org/10.1111/j.1365-313X.2004.02016.x.

94. Thornton B, Basu C. Real-time PCR (qPCR) primer design using free online software. Biochem Mol Biol Educ 2011;39(2):145-154. Epub 2011/03/30. https://doi.org/10.1002/bmb.20461. PubMed PMID: 21445907.

95. Livak KJ, Schmittgen TD. Analysis of relative gene expression data using real-time quantitative PCR and the 2(-Delta Delta C(T)) method. Methods. 2001;25(4):402-408. https://doi.org/10.1006/meth.2001.1262. PMID: 11846609 .

96. Colombian Ministry of Environment and Sustainable Development (Ministerio de Ambiente y Desarrollo Sostenible de Colombia). Resolución 1376. 2013. https://www.minambiente.gov.co/images/normativa/decretos/2 013/dec_1376_2013.pdf

\section{Publisher's Note}

Springer Nature remains neutral with regard to jurisdictional claims in published maps and institutional affiliations.
Ready to submit your research? Choose BMC and benefit from:
- fast, convenient online submission
- thorough peer review by experienced researchers in your field
- rapid publication on acceptance
- support for research data, including large and complex data types
- gold Open Access which fosters wider collaboration and increased citations
- maximum visibility for your research: over $100 \mathrm{M}$ website views per year
At BMC, research is always in progress.
Learn more biomedcentral.com/submissions 